Universidad de Lima

Facultad de Comunicación

Carrera de Comunicación

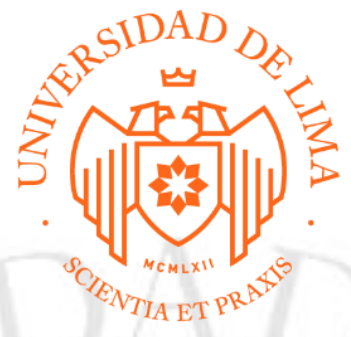

\title{
LANZAMIENTO DEL CONCENTRADO DE CHICHA MORADA: CHICHA YA!
}

Trabajo de Suficiencia Profesional para optar el Título Profesional de Licenciado en

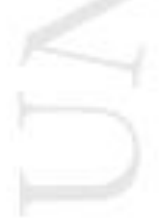

Comunicación

\section{Erik Thomas Segersbol Alvarez}

Código 20123111

$$
\begin{gathered}
\text { Lima - Perú } \\
\text { Junio de } 2019
\end{gathered}
$$




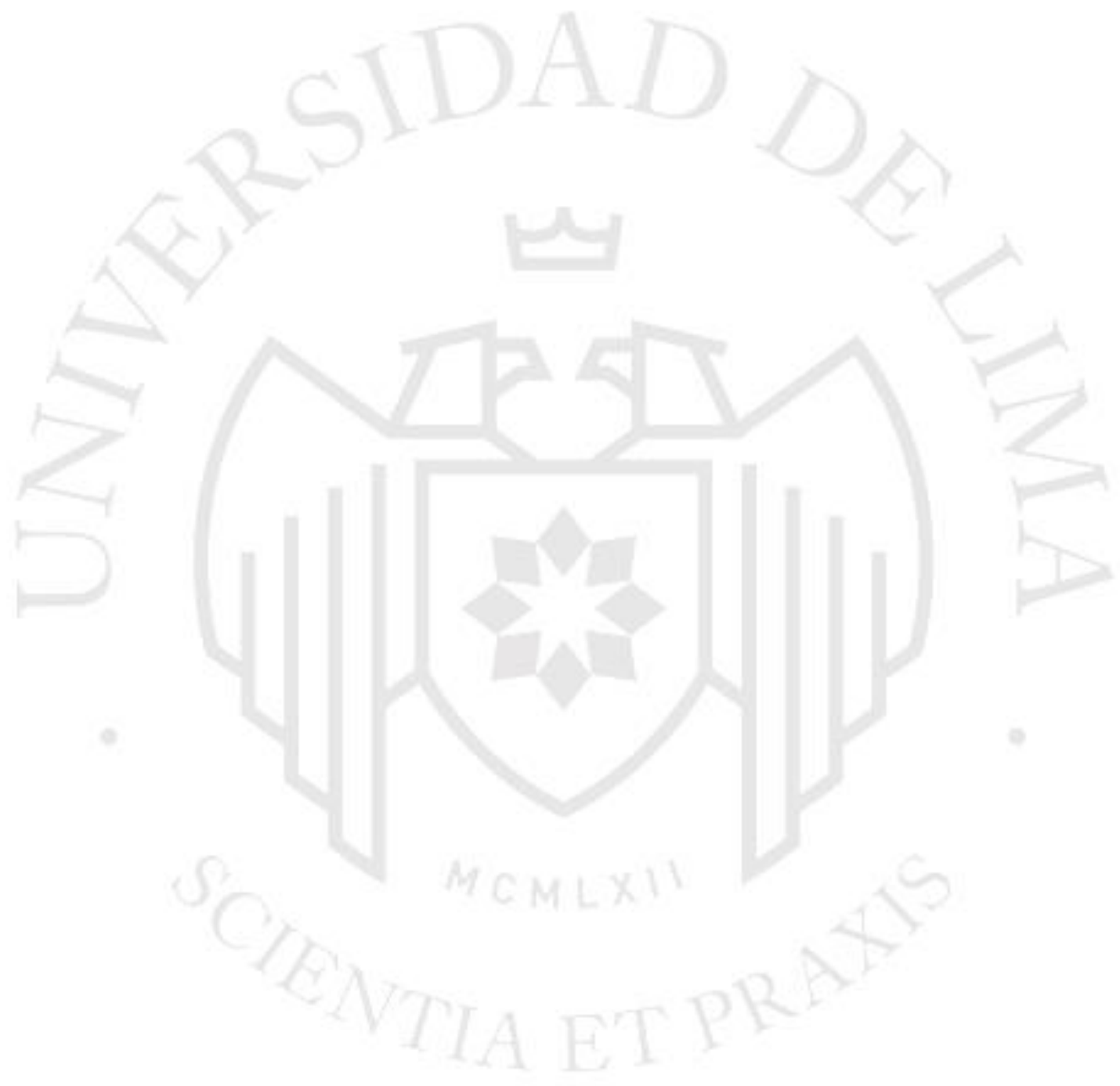




\section{LANZAMIENTO DEL CONCENTRADO DE}

CHICHA MORADA: CHICHA YA! 


\section{ÍNDICE}

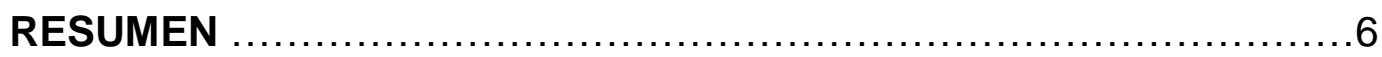

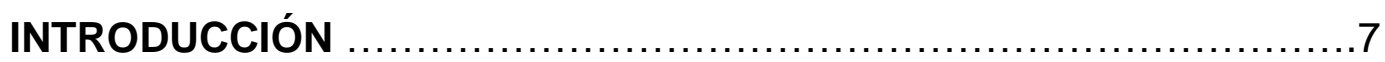

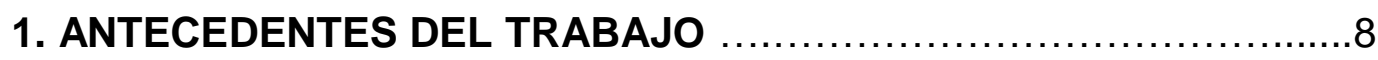

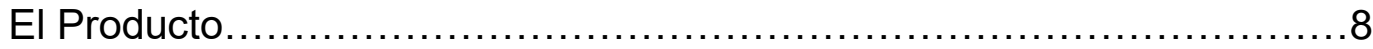

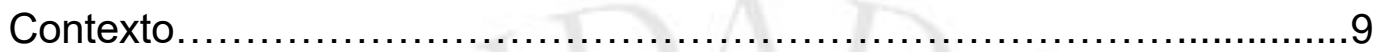

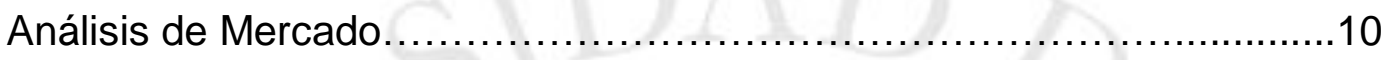

Análisis del Consumidor................................................ 12

Oportunidad, Objetivos y Posicionamiento ...................................13

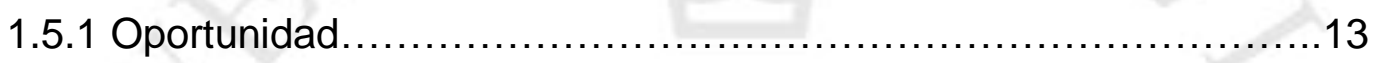

1.5.2 Objetivos de Markteting............................................... 14

1.5.4 Objetivo de Publicidad.................................................. 14

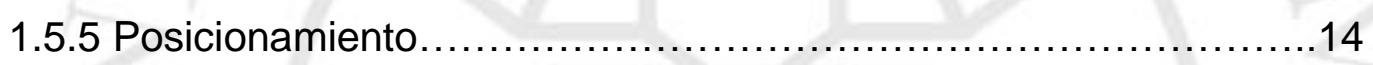

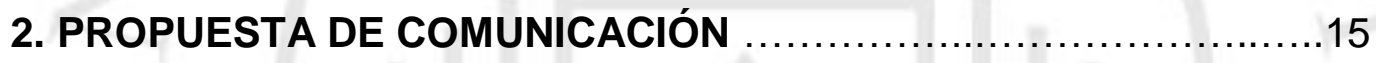

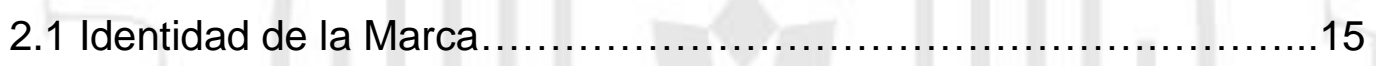

2.1.1 Identidad Verbal de la Marca..........................................15

2.1.2 Identidad Visual de la Marca......................................... 16

2.2 Estrategia Creativa ....................................................... 19

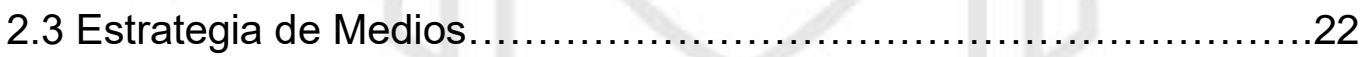

\section{EJECUCIÓN DE PROPUESTA DE}

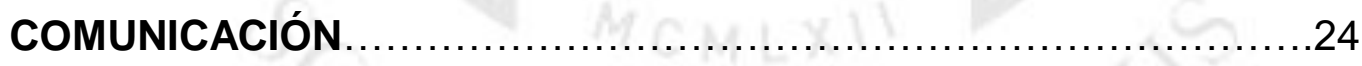

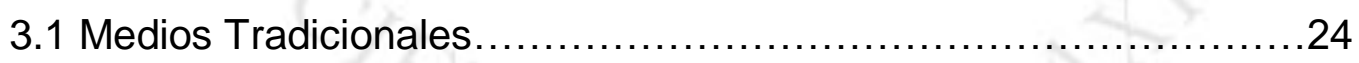

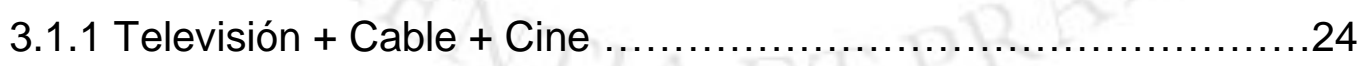

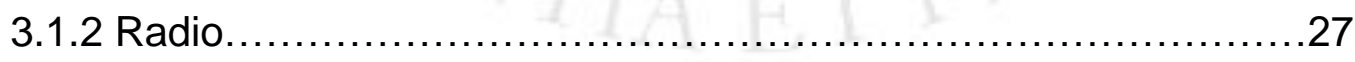

3.1.3 Publicidad Exterior ............................................. 28

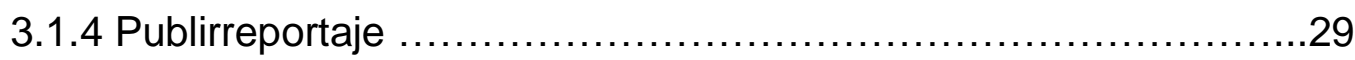

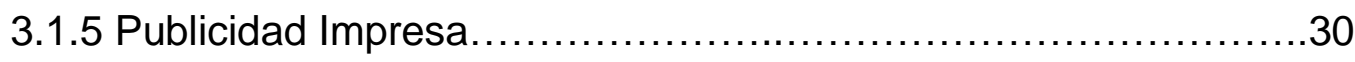

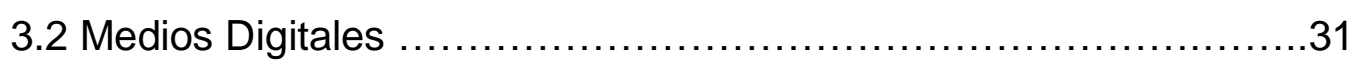

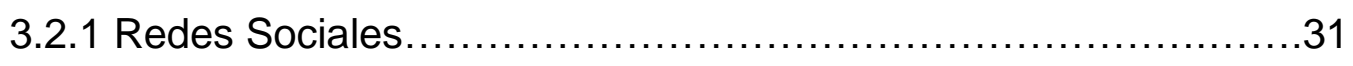

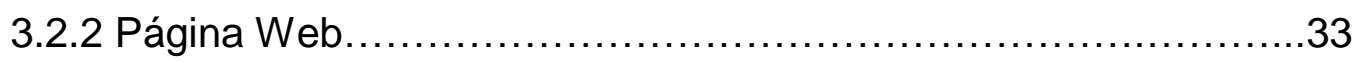

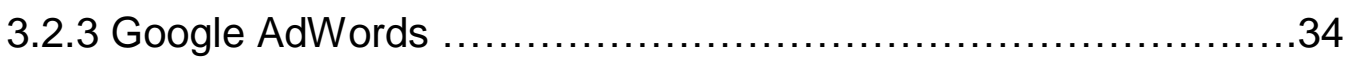


3.2.4 Cuadro de KPIs de medios digitales..............................

3.3 Medios Alternativos.................................................

3.3.1 Activación en Boulevard de Asia...................................37

3.3.2 Volanteo y degustaciones en Sur Chico y Ancón..................37

3.3.3 Degustaciones en Punto de Venta................................38

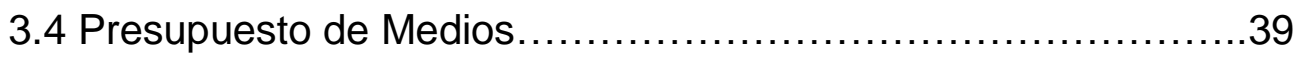

3.5 Distribución de Medios..............................................42

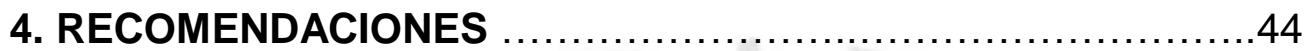

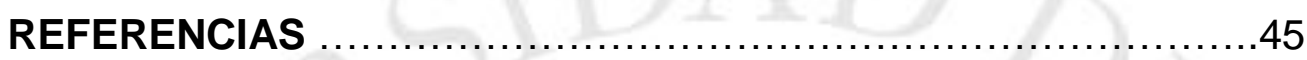

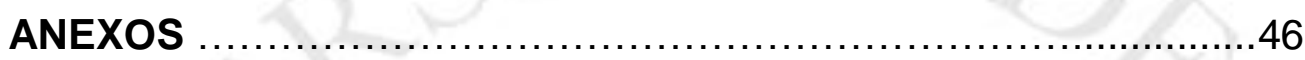




\section{RESUMEN}

Ante un mercado peruano que busca con más frecuencia productos $100 \%$ hechos con insumos naturales surge la oportunidad y necesidad de productos con esas características.

En este caso el tema trata del lanzamiento de un concentrado de chicha morada llamado Chicha Ya!. Lo que se busca con este lanzamiento es posicionar al concentrado como una marca que ofrece dos atributos muy importantes para el consumidor de hoy: productos naturales que no dañen su salud como lo hacen los productos procesados que cuentan con químicos y segundo que sean productos fáciles de preparar, es decir que no les quiten mucho tiempo en la cocina.

Para el eficaz lanzamiento se planteó una campaña integral de medios donde la sintonía entre tradicionales, digitales y alternativos logren captar la atención de los prospectos y que se incentive su compra así convirtiéndose en un producto solicitado cuando uno piense en elaborar una chicha morada $100 \%$ natural. 


\section{INTRODUCCIÓN}

El siguiente trabajo tiene como finalidad la creación de una campaña de lanzamiento destinada al mercado peruano de un concentrado de chicha morada $100 \%$ natural.

Los objetivos solicitados para el lanzamiento de este producto son: la identidad visual del mismo que se compone en la propuesta de nombre, logo y diseño de empaque, una campaña de comunicación integral para su lanzamiento en el mercado peruano la cual se compone de medios digitales (Facebook, YouTube, Instagram, Google AdWords y un Landing propio de la marca), tradicionales (TV, Cable, Radio, Medios Impresos y Vallas Exteriores) y por último en cuanto a medios alternativos se tendrá material de punto de venta (para la degustación del producto) y dos activaciones de lanzamiento. La campaña se sostendrá con una inversión de US\$500,000.

Para el cumplimiento eficaz de los objetivos se empezó con una descripción detallada del producto, se continuó con una investigación del contexto y mercado, luego se analizaron los puntos de interés del público objetivo que en este caso son amas de casa y se definieron los objetivos y posicionamiento.

Finalmente, bajo el sustento de la investigación previamente mencionada se diseñó el nombre y esencia visual del producto, se planteó el concepto creativo y se finalizó con su ejecución proyectada en distintos medios de comunicación como parte de un lanzamiento integral. 


\section{ANTECEDENTES DEL TRABAJO}

Para un buen lanzamiento de marca debemos tener primero una vista clara del contexto actual al que entraremos, por ello en este apartado analizaremos las características del producto, el contexto actual, el mercado al cual se incursionará, el perfil del consumidor y un breve planteamiento de los objetivos y posicionamiento deseado.

\subsection{El Producto}

Chicha Ya! es un concentrado de chicha morada elaborado en su totalidad con insumos naturales los cuales son: maíz morado, membrillo, piña, limón, clavo de olor y canela. Ingredientes que se encuentran en la clásica receta de la chicha morada, una bebida muy popular y tradicional en el Perú. Cabe rescatar que todos los insumos provienen de agricultores locales por lo que el producto se caracteriza por ser $100 \%$ peruano.

El concentrado el cual necesita refrigeración viene en una presentación de 500 $\mathrm{ml}$ la cual rinde $2.5 \mathrm{~L}$ y está contenido en una botella de vidrio $100 \%$ reciclable. Su forma de uso es la siguiente: Diluir los $500 \mathrm{ml}$ en $2 \mathrm{~L}$ de agua, remover, servir y disfrutar. Su sabor busca ser como el de antaño, el natural y no contiene azúcar.

Entre sus propiedades beneficiosas para el cuerpo humano cuenta con "un alto porcentaje de antocianinas, un tipo de flavonoides complejos que se caracterizan por tener un importante efecto antioxidante al apoyar la regeneración de los tejidos, fomentar el flujo de la sangre, reducir el colesterol, entre otras" (Ecured, 2019). En cuanto a esta característica se comunicará que posee antioxidantes para no confundir al consumidor con términos complejos. 
El producto está destinado a las amas de casa peruanas del NSE ABC, las cuales muchas veces no tienen el tiempo para elaborar una chicha morada clásica y este se presenta como una alternativa natural y rápida de preparar.

Su distribución será en los supermercados más importantes del país como Wong, Metro, Plaza Vea, Vivanda, Tottus y Makro y en algunas bodegas clave de las ciudades con más población del país: Lima, Arequipa, Trujillo, Cuzco y Piura.

\subsection{Contexto}

El Perú ha entrado en una nueva tendencia de consumo de productos alimenticios que se está dando alrededor de todo el mundo. Para detallar este argumento líneas abajo se mencionan estamentos de dos compañías de investigación mundiales, Kantar y Nielsen citadas de dos portales web.

El Diario Correo cita en su artículo web " 5 datos sobre el consumo de bebidas de fruta en el Perú" lo siguiente: "Un reciente estudio de Kantar WorldPanel indicó que, para el 2019 , cerca del $87 \%$ de los hogares peruanos demandará a las empresas el desarrollo de productos cada vez más saludables" (como se citó en Diario Correo, 2019). Esto nos indica que Chicha Ya! está entrando a un mercado que encuentra positivo los productos saludables y libres de químicos. Según en Mercado Negro, Raúl Díaz comenta (2018):

Un estudio realizado para el informe Trends Around the World de Nielsen revela que para el $77 \%$ del total de encuestados globales los ingredientes naturales fueron un factor muy o moderadamente determinante para elegir un snack. Además, el informe señala que la tendencia es que los consumidores reduzcan el consumo de alimentos y bebidas que son típicamente altos en grasa, azúcar o sodio." (como se citó en el artículo de Mercado Negro, 2018).

Esta data es interesante puesto nos pone en el contexto que en Perú los consumidores realmente están mirando hacia una alimentación más saludable y que el tener ingredientes naturales en el etiquetado es un determinante de compra hoy en día. 
Todo esto también ha captado el interés del estado peruano en los últimos años. La acción principal que ha desarrollado este es la promulgación de la Ley de la Promoción de la Alimentación Saludable para Niños, Niñas y Adolescentes y la fecha límite de puesta en práctica de las normas del etiquetado según el diario El Comercio será el 19 de junio de 2019.

En cuanto al desarrollo de la ley en el tiempo, se cita un resumen plasmado en un artículo web del Diario El Comercio donde se dice que esta "fue promulgada por el presidente Humala en mayo de 2013. Su reglamento recién lo aprobó en abril de 2017 el presidente Kuczynski. Finalmente, el "Manual de advertencias publicitarias", fue aceptado en junio de 2017 por la ministra de Salud, Pessah" (Diario El Comercio, 2019).

En este contexto Chicha Ya! con sus seis ingredientes 100\% naturales tendrá un punto de ventaja sobre la competencia general de bebidas al no contar con octógonos de advertencia en su etiquetado representando así un refuerzo de su posible propuesta de promesa y soporte.

\subsection{Análisis de Mercado}

Para el análisis de la competencia utilizaremos una parte del "brand positioning template" la cual es definir los tres mercados que influyen como competencia del producto Chicha Ya!

Mercado Simple: Concentrados de chicha morada Mercado: Concentrados de bebidas naturales y sobres de jugos instantáneos Mercado Ampliado: Bebidas frutadas sin alcohol

Para el mercado se tienen a los sobres de concentrados de jugos en polvo como Zuko y Negrita Frutísimos de Alicorp que tienen como objetivo lo mismo que el producto a lanzar: Obtener una bebida lista para consumir en pocos minutos, sin embargo, están cuentan con químicos y el producto a lanzar no, por lo que esta sería la ventaja diferencial en este sector. 
Según Euromonitor International "los consumidores peruanos están aumentando su interés por productos que sean naturales y saludables. En general tienen una alta tendencia por productos con proveniencia casera, los cuales son considerados más saludables y además evitan bebidas con ingredientes artificiales y colorantes" (Euromonitor International, 2019)

En cuanto a la plaza todos se distribuyen en casi los mismos lugares y el contenido de cada uno de los productos rinde aproximadamente lo mismo, de $2 \mathrm{~L}$ a $2.5 \mathrm{~L}$.

\begin{tabular}{|l|l|l|l|}
\hline Marca & Zuko & $\begin{array}{l}\text { Negrita } \\
\text { Frutísimos }\end{array}$ & Chicha Ya! \\
\hline Presentaciones & $\begin{array}{l}\text { Sobre de 15 gr } \\
\text { rinde 2L }\end{array}$ & $\begin{array}{l}\text { Sobre de 20 gr } \\
\text { rinde 2L }\end{array}$ & $\begin{array}{l}\text { Botella de } \\
500 \mathrm{ml} \text { rinde } \\
2.5 \mathrm{~L}\end{array}$ \\
\hline Distribución & $\begin{array}{l}\text { Supermercados } \\
\text { y bodegas }\end{array}$ & $\begin{array}{l}\text { Supermercados } \\
\text { y bodegas }\end{array}$ & $\begin{array}{l}\text { Supermercados } \\
\text { y bodegas }\end{array}$ \\
\hline Precio & S/0.99 & S/1.10 & S/ 6.00 \\
\hline
\end{tabular}

Fuente: Elaboración propia

En cuanto al mercado simple se tiene como competencia directa de Chicha Ya! a varias marcas que cuentan con concentrados de la bebida "chicha morada", la primera observación es que uno del cuadro de abajo está destinado para consumo industrial, es decir un consumo industrial business to business, y no está presente en los puntos de venta a los cuales queremos incursionar por lo que no serían una amenaza directa en el punto de venta, sin embargo si hay tres marcas de concentrados de chicha morada en puntos de venta: Naturale, Sayani y Cosecha de Oro. Estas tres podrían ser una amenaza puesto ya cuentan con el producto y la distribución. La que resalta más es Cosecha de Oro ya que se 
vende en lugares similares a los que incursionará Chicha Ya! y tiene el mismo peso y rendimiento de $2.5 \mathrm{~L}$.

En el caso de TokeFrut y Valle Fértil (no se encuentra en el cuadro por falta de información) solo les falta la distribución de negocio a consumidor final para que representen una amenaza al producto a lanzar por su presencia en el mercado.

\begin{tabular}{|c|c|c|c|c|c|}
\hline $\begin{array}{l}\text { Marcas de } \\
\text { Concentrados de } \\
\text { Chicha Morada }\end{array}$ & Naturale & Sayani & $\begin{array}{l}\text { Cosecha de } \\
\text { Oro }\end{array}$ & TokeFrut & Chicha Ya! \\
\hline Presentaciones & $\begin{array}{l}\text { Bolsa } 2 \mathrm{~L} \\
\text { rinde de } \\
8 \mathrm{~L} \text { a } 12 \mathrm{~L}\end{array}$ & $\begin{array}{l}\text { Botella de } 1 \mathrm{~L} \\
\text { rinde } 6 \mathrm{~L} . \\
\text { Botella de } 2 \mathrm{~L} \\
\text { rinde } 8 \mathrm{~L} \quad \text { a } \\
12 \mathrm{~L}\end{array}$ & $\begin{array}{l}\text { Bolsa de } 500 \mathrm{gr} \\
\text { rinde } 2.5 \mathrm{~L}\end{array}$ & $\begin{array}{l}\text { Bolsa } \\
400 \mathrm{gr}\end{array}$ & $\begin{array}{l}\text { Botella } 500 \mathrm{ml} \\
\text { rinde } 2.5 \mathrm{~L}\end{array}$ \\
\hline Distribución & $\begin{array}{l}\text { Makro, } \\
\text { Mayorsa y } \\
\text { Maxi } \\
\text { Ahorro }\end{array}$ & $\begin{array}{lr}\text { Hong } & \text { Kong } \\
\text { Market, } & \text { La } \\
\text { Casa de } & \text { los } \\
\text { Ravioles } & \text { y } \\
\text { otras } & \\
\text { bodegas } & \end{array}$ & $\begin{array}{l}\text { Wong } \\
\text { Ov.Gutierrez, } \\
\text { entre otros } \\
\text { supermercados }\end{array}$ & $\begin{array}{l}\text { Por pedic } \\
\text { industrial }\end{array}$ & $\begin{array}{l}\text { Supermercados } \\
\text { y bodegas }\end{array}$ \\
\hline Precio & $\mathrm{S} / 13.00$ & $\mathrm{~S} / 16.70$ & S/5.99 & $\mathrm{N} / \mathrm{A}$ & $\mathrm{S} / 6.00$ \\
\hline
\end{tabular}

Fuente: Elaboración propia.

\subsection{Análisis del consumidor}

El concentrado de chicha morada "Chicha Ya!" está destinado para las amas de casa peruanas del nivel socioeconómico A, B y C quienes según Ipsos (2018) representan al $52 \%$ del total de las amas de casa peruanas (p.13). 
Además según Ipsos (2018), el 90\% de ellas cuentan en sus familias con al menos un hijo (p.14). Por ello se asume que entre sus labores estaría el cuidado de la familia lo que les restaría tiempo para los quehaceres del hogar.

También, ya para el 2017 según Ipsos (2018) el 52\% de las amas de casa ya cuentan con una labor adicional a los quehaceres del hogar, es decir trabajo de jornada completa, part-time y otros tipos de trabajo (p.23). Esto nos indica que este también sería un indicador que las amas de casa cuentan con menos tiempo libre en su día a día y por ello buscan productos que les simplifiquen los tiempos en la cocina.

Ellas son quienes valoran mucho los productos que sean naturales. Según Mercado negro últimamente hay una tendencia global, es decir que engloba a todos los públicos objetivos, en el sector de comidas y bebidas la cual ha llegado al Perú. "En esta los consumidores están adoptando una postura 'back to basics', donde se centran en el consumo de productos frescos y menos procesados" (Mercado Negro, 2019).

En cuanto a los estilos de vida de Arellano las ubicamos en "modernas" debido a que citando el estudio de Arellano tienen como características de compra las siguientes:

Les gusta proyectar una buena imagen y cuidar su estética, dan prioridad a los beneficios abstractos de las cosas que compran: Usan marcas como símbolo social y señal de calidad, no tanto al precio y les interesan los productos que ofrezcan reducir el tiempo y esfuerzo en las labores del hogar y que eviten hacerlas sentir solamente "amas de casa" (Arellano, 2019).

Esta última afirmación es relevante para Chicha Ya! puesto que el producto se presta para facilitar su labor de cocina en el hogar.

\subsection{Oportunidad, Objetivos y Posicionamiento}

\subsubsection{Oportunidad}


Al promulgarse la ley de alimentación saldable muchas amas de casa han decidido seguir la tendencia de consumo de productos naturales para cuidarse a ellas y a sus familias, el problema es que cuentan con poco tiempo en su día a día para dedicar tiempo a elaborar una chicha morada $100 \%$ natural. Chicha Ya! Se presentaría como una alternativa que resuelva esas dos necesidades.

\subsubsection{Objetivos de Marketing}

Posicionar el concentrado de chicha morada Chicha Ya! como una alternativa $100 \%$ natural para las amas de casa que tienen poco tiempo para la cocina y quieren disfrutar de una chicha morada como las de antaño, sin preservantes ni colorantes. Se busca que con el lanzamiento, el producto pueda convertirse en una opción frecuente cuando un ama de casa elija un producto para elaborar una bebida.

\subsubsection{Objetivo de Publicidad}

La publicidad debe persuadir al grupo objetivo para que adquiera y consuma el nuevo concentrado de chicha morada Chicha Ya!, el cual es la alternativa que ofrece una chicha morada $100 \%$ natural con poco tiempo de elaboración.

\subsubsection{Posicionamiento}

Según el brief a grandes rasgos el posicionamiento deseado es: "Para las amas de casa modernas y prácticas, Chicha Ya! es la verdadera chicha morada, elaborada con la receta tradicional casera, basada en la concentración del maíz morado con una combinación de frutas y especias naturales. Es una bebida sana porque no contiene saborizantes ni preservantes, ni azúcar añadida." Adicional a esto es una bebida natural fácil y rápida de preparar.

Con todo esto, el posicionamiento será: Natural y conveniente. 


\section{PROPUESTA DE COMUNICACIÓN}

\subsection{Identidad de la Marca}

\subsubsection{Identidad Verbal de la Marca}

Nombre:

Para el concentrado de chicha morada se ha elegido el nombre "Chicha Ya!", este es un nombre que alude a lo racional por su primera palabra y a lo funcional por la segunda palabra la cual cuenta con un signo de exclamación para realzarla.

Su construcción se basa en dos palabras: Chicha la cual está resaltada de verde (palabra usualmente utilizada en la vida cotidiana peruana para referirse a la bebida chicha morada, un brebaje muy popular en el país que es consumido con mucha frecuencia a lo largo del año) y Ya! la cual está resaltada de magenta (palabra que nos remite a la inmediatez, muy usada en conversaciones peruanas, es utilizada a menudo y su entonación puede darle diversos significados, en este caso "ya" ha sido aumentado por el signo de exclamación para afianzar la inmediatez que proporciona el producto). Estas palabras han sido elegidas bajo un ejercicio que se compone en dividir los atributos físicos, sensoriales y de uso del producto para así combinar varias palabras con el fin de que el producto tenga una identidad acorde a lo que ofrece.

\begin{tabular}{|l|l|l|}
\hline Físico & Sensorial & De uso \\
\hline Concentrado & Delicioso & Instantáneo \\
\hline Chicha Morada & Fresco & Conveniente \\
\hline Líquido & Frío & Fácil \\
\hline Morado & Saludable & Práctico \\
\hline Natural & & Ahora / Ya \\
\hline
\end{tabular}

Fuente: Elaboración Propia 
Para una marca es esencial que su nombre cumpla con los requisitos de ser simple de pronunciar y de ser una o un conjunto de palabras de pocas letras, esto deriva a que el proceso de recordación sea más fluido como sería en el caso de Chicha Ya!.

Slogan de refuerzo:

Para reforzar la comunicación se ha agregado como subtitulo "concentrado de chicha morada $100 \%$ natural", también su estructura se ha sacado del cuadro de atributos que se encuentra más arriba. Esto nos ayuda a reforzar el posicionamiento deseado de que se le vea a la marca como una opción natural y conveniente.

\subsubsection{Identidad visual de la Marca}

Logotipo:
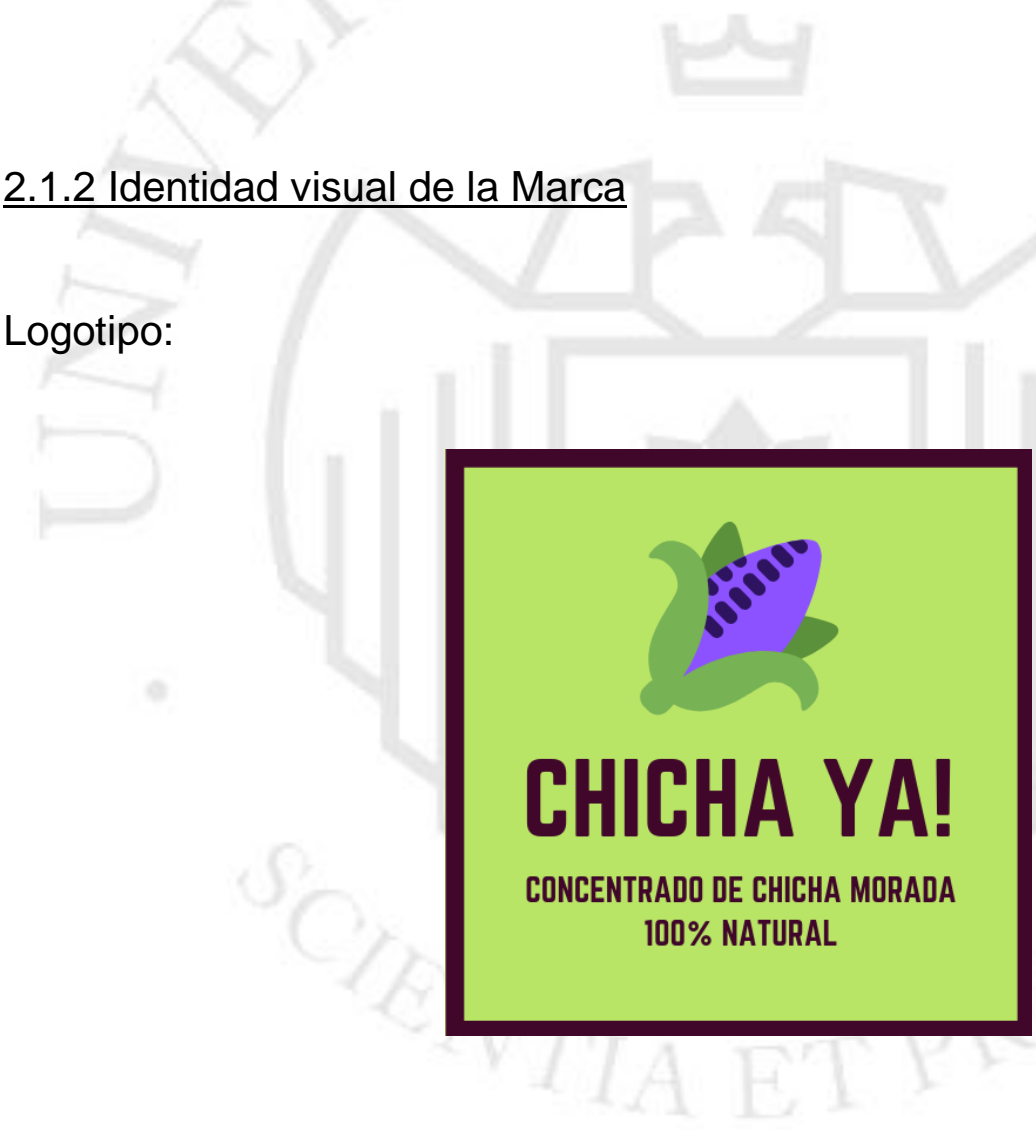

Para el logotipo de la marca se ha utilizado un estilo minimalista y directo, se ha puesto como isotipo principal a la mazorca del maíz morado con un estilo simple y poco recargado, la elección del icono tiene curvas que la hacen dinámica y agradable a la vista, además a primer vistazo uno identifica de que trata el producto, el ícono es importante puesto es lo que primero se ve antes de leer lo 
demás. Se ha complementado como isologo al vector del maíz morado, el nombre de la marca "Chicha Ya!", debajo de la composición vemos de que trata el producto con un slogan de refuerzo: "Concentrado de chicha morada 100\% natural". Esta construcción afianza la comunicación de que el producto es una base para hacer chicha morada $100 \%$ natural y no una bebida para tomarla al instante. Toda la composición recae en un cuadrado con interior verde claro y un marco guinda oscuro, colores principales de la marca y elegidos en base a la categoría.

Tipografía:

Se eligió la tipografía Norwester de tipo San Serif geométrico. Esta está solo disponible para que se vea en mayúsculas y tiene un estilo que se pega a lo minimalista, es muy legible y se adapta muy bien al estilo visual de la marca.

\section{FONTS}

\section{NORWESTER AABBCCDDEEEFFGGHHIIJJKKLLMM

Paleta de colores:

Se han utilizado los colores clásicos de la chicha morada los cuales son los guindas y morados, también se ha utilizado el verde como color clave para denotar que es un producto $100 \%$ natural. Toda la paleta ha sido elegida para poder resaltar frente a la competencia, pero sin dejar de lado los colores que predominan en el mercado de productos a base de chicha morada. 


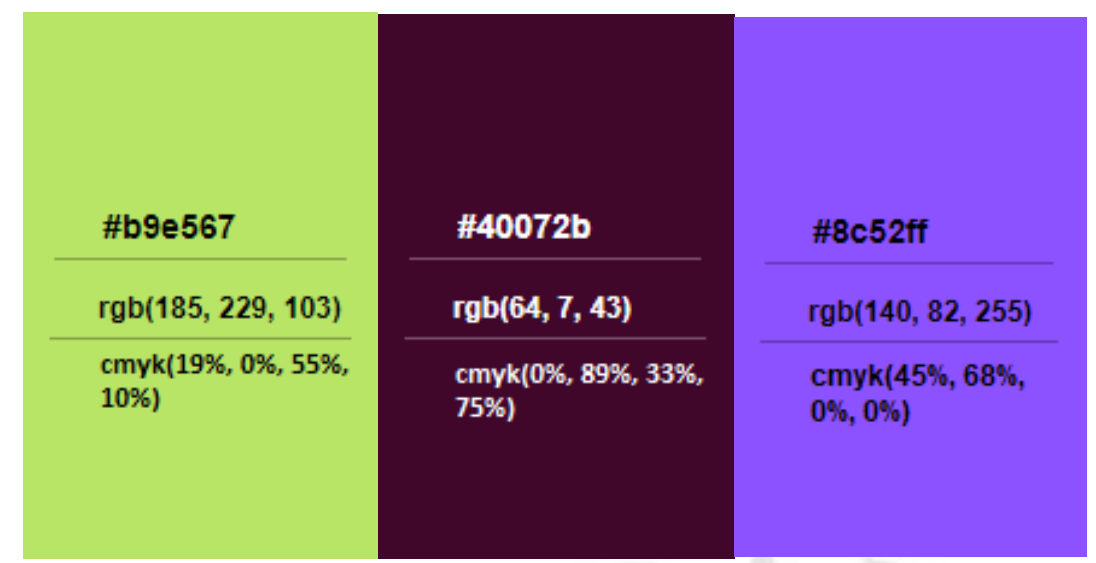

Packaging y Etiquetado:

Para el empaque se busca que la botella sea $100 \%$ reciclable para mantener la promesa de que es $100 \%$ natural y amable con el planeta, por ende, cuenta con una botella de vidrio para contener los $500 \mathrm{ml}$ del concentrado y una tapa de plástico la cual es elaborada con plástico reciclado proveniente de fuentes responsables.

En la etiqueta del empaque solo se han utilizado los dos colores principales de la marca en su mayoría para reforzar su identidad visual. Cuenta con tres partes, la primera es un sticker que garantiza al consumidor que su producto no ha sido manipulado por nadie más, se ha aprovechado el sticker para comunicar que está hecho con ingredientes $100 \%$ naturales y que rinde $2.5 \mathrm{~L}$. La segunda es la etiqueta principal donde se encuentra el logotipo, los ingredientes, los atributos del producto ( sin azucares, sin colorantes, sin preservantes, con antioxidantes) y cuantos $\mathrm{ml}$ contiene el producto que en este caso son $500 \mathrm{ml}$. Por último en la etiqueta de la retira, la que va en la parte posterior del envase, se ha puesto un mensaje de cuidado del medio ambiente, las instrucciones de uso del producto, un mensaje de mantener refrigerado este producto y un texto que dice "elaborado con ingredientes $100 \%$ peruanos" para así reforzar el mensaje alternativo de que Chicha Ya! es natural y sus insumos provienen de fuentes $100 \%$ peruanas. 


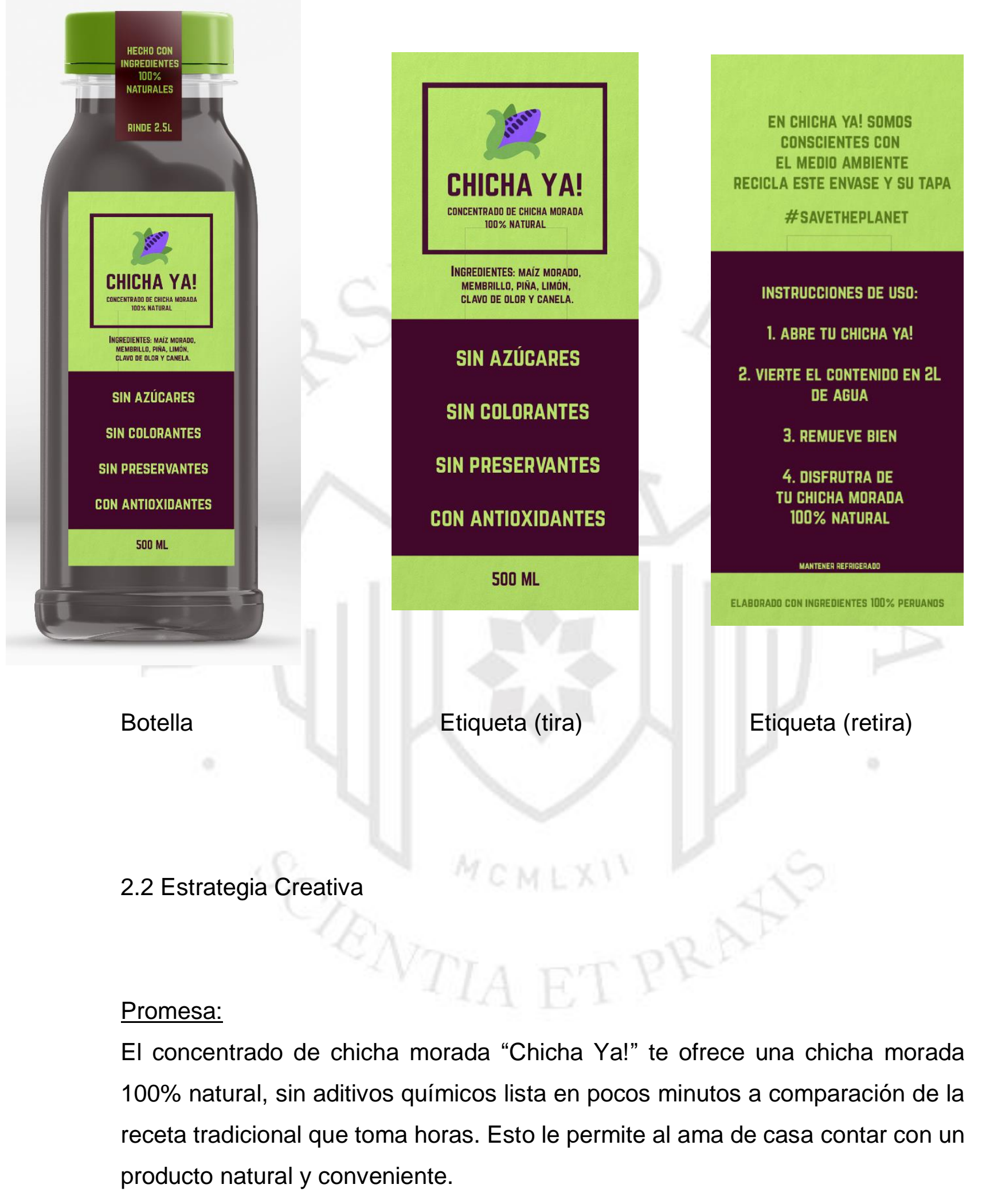


Soporte:

El concentrado de chicha morada Chicha Ya! está elaborado con insumos 100\% naturales (maíz morado, membrillo, piña, limón, clavo de olor y canela) y su preparación toma menos de tres minutos al ser su preparación tan simple como combinar el concentrado con agua.

\section{Tono de la publicidad:}

El mensaje publicitario que se dará a lo largo de la campaña será de tipo racional y seguirá la línea de "Tu chicha morada 100\% natural lista en menos de 3 minutos para que puedas disfrutar más de tu día" Su personalidad será el de una persona astuta y jovial por alimentarse bien.

\section{Propuesta de guion para el spot de tv:}

La propuesta del guion nos sirve como pieza madre para el despliegue de la campaña por eso se ha considerado ponerla como parte de la estrategia creativa.

Es un sábado normal en un hogar peruano. Las amas de casa siempre buscan avanzar cosas, pero también buscan descansar y disfrutar del tiempo en familia. Por ello se quiere mostrar un contraste entre una señora que prepara la chicha tradicional y otra que la prepara con el concentrado de chicha morada Chicha Ya!, este contraste quiere mostrar que ambos productos son lo mismo al final pero que uno te permite de disponer más de tu tiempo con el que cuentas en el día.

El estilo que se le dará a las tomas será como Al Fondo Hay Sitio, planos conjuntos con colores cálidos y con una estructura de guion que busca ir al grano.

Guion:

\begin{tabular}{|l|l|l|}
\hline IMAGEN & PLANO & SONIDO \\
\hline $\begin{array}{l}\text { Pantalla Dividida: A la } \\
\text { izquierda Julia con una }\end{array}$ & $\begin{array}{l}\text { Plano conjunto en } \\
\text { ambas pantallas }\end{array}$ & $\begin{array}{l}\text { Voz en off: Son las 12 P.M. } \\
\text { y Julia y Marta van a }\end{array}$ \\
\hline
\end{tabular}




\begin{tabular}{|c|c|c|}
\hline $\begin{array}{l}\text { jarra de agua y su } \\
\text { botella de Chicha Ya! } \\
\text { A la derecha Marta con } \\
\text { sus ingredientes en la } \\
\text { mesa. }\end{array}$ & & $\begin{array}{l}\text { preparar una chicha } \\
\text { morada } 100 \% \text { natural. }\end{array}$ \\
\hline $\begin{array}{l}\text { Pantalla Dividida: A la } \\
\text { izquierda Julia vertiendo } \\
\text { el concentrado en el } \\
\text { agua. A la derecha } \\
\text { Marta metiendo el maíz } \\
\text { y frutas a la olla }\end{array}$ & $\begin{array}{l}\text { Plano conjunto en } \\
\text { ambas pantallas }\end{array}$ & $\begin{array}{l}\text { Voz en off: Marta empieza y } \\
\text { Julia ya está por acabar }\end{array}$ \\
\hline $\begin{array}{l}\text { Julia removiendo el } \\
\text { contenido }\end{array}$ & Plano cenital detalle & $\begin{array}{l}\text { Efecto de Sonido: Cuchara } \\
\text { removiendo la chicha } \\
\text { morada dentro de la jarra } \\
\text { de vidrio. } \\
\text { Voz en off: Natural y fácil de } \\
\text { preparar }\end{array}$ \\
\hline $\begin{array}{l}\text { Julia sirviendo la chicha } \\
\text { en } 03 \text { vasos. } \\
\text { Icono } 3 \text { minutos esquina } \\
\text { superior derecha con } \\
\text { una cara de aprobación. }\end{array}$ & Plano conjunto & $\begin{array}{l}\text { Voz en on: ¡Chicos ya está } \\
\text { la chicha! }\end{array}$ \\
\hline $\begin{array}{l}\text { Familia en un mueble } \\
\text { viendo tv tomando } \\
\text { chicha }\end{array}$ & Plano conjunto & $\begin{array}{l}\text { Voz en on: Mm delicioso } \\
\text { ma. } \\
\text { Voz en off: Disfruta más de } \\
\text { tu tiempo }\end{array}$ \\
\hline Packshot del producto & Plano medio & $\begin{array}{l}\text { Chicha Ya! } 100 \% \text { natural y } \\
\text { lista en menos de } 3 \\
\text { minutos. Disfrútala. }\end{array}$ \\
\hline $\begin{array}{l}\text { Marta sudando recién } \\
\text { terminando su chicha } \\
\text { morada -lcono } 1 \text { hora } \\
\text { esquina superior }\end{array}$ & Plano conjunto & $\begin{array}{l}\text { Voz en off: ¿Recién } \\
\text { terminas? }\end{array}$ \\
\hline
\end{tabular}


derecha con cara de cansancio.

\subsection{Estrategia de Medios}

La campaña de lanzamiento durará 90 días, será integral y contará con medios digitales, tradicionales y alternativos. La fecha de inicio será el 8 de enero del 2020, seis meses después aproximadamente de la fecha límite para que las marcas relancen sus productos con etiquetado con octógonos, el cual es un proceso donde varias marcas se están adaptando lentamente y Chicha Ya! quiere aprovechar la situación para un lanzamiento acorde a la situación, la cual permite realzar el atributo de $100 \%$ natural al no tener octógonos en su empaque ni publicidad. La campaña será de lanzamiento, no se ha propuesto intriga porque se quiere entrar con fuerza y de frente al mercado y los días en verano son valiosos, cada día cuenta.

En la actualidad una gran parte del público objetivo cuenta con un alto porcentaje de acceso a los medios digitales, según Ipsos en el 2018 a nivel global el 57\% de las amas de casa peruanas ya son digitales, 6\% más que en el 2017 (Ipsos, 2018, p.40). Todo esto proyecta a que esta tendencia esté en aumento. Por ello del lado digital la campaña de lanzamiento contará con publicidad en Facebook, YouTube, Instagram, un landing propio de la marca para utilizar la metodología inbound y anuncios en Google.

En cuanto a los medios tradicionales habrá un spot de 30 segundos que será difundido en un canal nacional, por cable y en las salas de una cadena de cines, cinco vallas estáticas, publirreportajes, auspicios, publicidad en revistas y un spot radial.

Para finalizar en cuanto a los medios alternativos habrá una activación en un boulevard del sur que tiene un alto índice de tráfico en el verano y en cuatro playas del Sur Chico y Ancón, asimismo habrá degustaciones en puntos de venta con el soporte de un visicooler de la marca en supermercados. 
Este plan de medios nos sirve para consolidar el ecosistema general de medios para el lanzamiento de la campaña y lo que se busca es que a través de la frecuencia y alcance en distintos medios se pueda ganar un lugar dentro del sector al que se quiere incursionar, siempre manteniendo continuidad en la exposición del mensaje. 


\section{EJECUCIÓN DE PROPUESTA DE COMUNICACIÓN}

Para la correcta ejecución de la campaña se mostrará el detalle de cada uno de los medios de comunicación elegidos para esta, primero se empezará con los medios tradicionales, luego los digitales y al final los alternativos. Al final de la descripción de actividades por medio se puede encontrar el cuadro de presupuesto y la matriz general de medios.

\subsection{Medios tradicionales}

\subsubsection{Televisión + Cable + Cine}

Según Ipsos 2018, las amas de casa peruanas poseen televisores en sus hogares, exactamente más del 71\% (Ipsos, 2018, p.44).

En cuanto a los canales con más rating de señal abierta para este público encontramos América Tv y Frecuencia Latina para los NSE B y C, sin embargo solo se trabajará con el canal 4 por temas de presupuesto. También se invertirá en cable con los canales de TNT y FOX los cuales tienen mejor llegada a los NSE A y B. Se quiere alcanzar una media de 100 a 200 TRPs en cada caso, esto para no sobre saturar al público pero tampoco dejar de lado la frecuencia del mensaje que requiere un producto nuevo en el mercado.

En cuanto al canal 4, más conocido como América TV, se emplearán dos formatos para promocionar el concentrado de chicha "Chicha Ya!", la primera acción es el spot que se difundirá en horario estelar AAA, específicamente de 8:30 pm a 9:30 pm cuando estén emitiendo De Vuelta al Barrio, esto será bajo un plan de auspicio donde se tendrá presencia en la presentación y despedida, también se estará presente en la cola de la promoción y se tendrá 1 aviso de 30s por fecha. La segunda acción es un product placement en el programa En Boca de Todos donde se exhibirá el producto y se beberá la chicha ya lista en el programa. El conductor dirá "Que bueno que por fin haya un concentrado de 
chicha morada $100 \%$ natural y lo mejor es que la preparé en menos de 3 minutos, gracias Chicha Ya!".

También se lanzará el spot por cable, específicamente en los canales TNT y FOX, este separado en veinticuatro fechas, específicamente sólo jueves, sábados y domingos una vez por fecha por canal. La elección de estos es que según Ipsos 2017, En Lima el NSE A y B cuentan en un $98 \%$ y $94 \%$ respectivamente con TV de paga" (p.23)

También según Ipsos 2018, TNT en el cuadro de canales más frecuentados, tiene el mayor porcentaje de mujeres, con $12 \%$ y el rango de edad mayor con $19 \%$ del total, a eso le sigue FOX con un $9 \%$ y un 17\% respectivamente (p.25). Estos datos nos afianzan de que el spot llegue de manera más específica a estos NSE, a diferencia del canal 4 que tiene mayor frecuencia por parte del NSE B y C.

Por último también se replicará el spot en Cineplanet Super Premium (cines donde el ticket de compra es más caro, por ende están dirigidos al NSE A,B y C), donde se busca alcanzar a más de 600,000 personas entre los 06 combinados de la categoría los cuales son: Alcázar, San Borja, Primavera, San Miguel, Salaverry y La Molina. La segmentación del público objetivo no es exacta pero el impacto es considerable como complemento para un lanzamiento de marca. 


\section{Storyboard:}

\section{S P O T: С H I С H A Y A !}

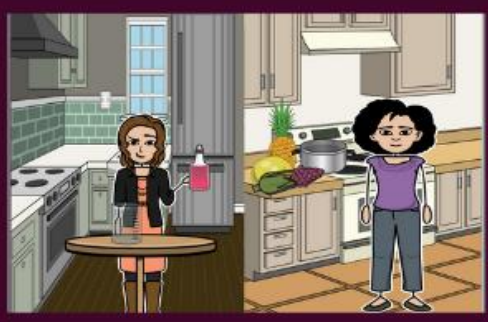

ESCENA 1 - PANTALLA DIVIDIDA - PLANO CONJUNTO

Voz en off: Son las Il am y Marta y Julia van a preparar una chicha morada $100 \%$ natural

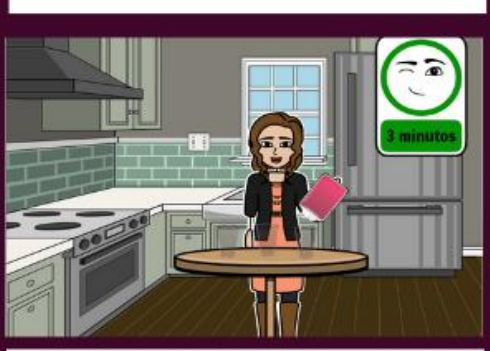

ESCENA 4 - PLANO CONJUNTO

Voz en on: ;Chicos ya está la chicha!
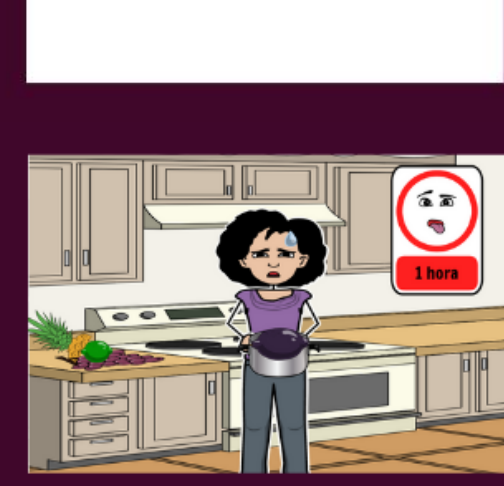

ESCENA 7 - PLANO CONJUNTO

Voz en off: ¿Recién terminas?

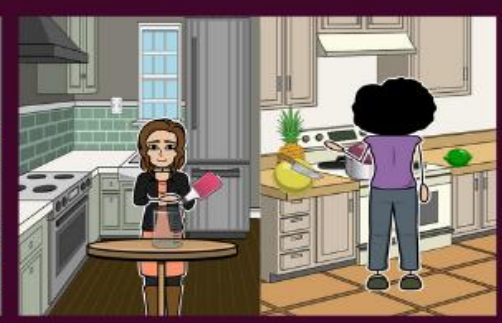

ESCENA 2 - PANTALLA DIVIDIDA - PLANO CONJUNTO

Voz en off: Marta empieza y Julia ya está por terminar

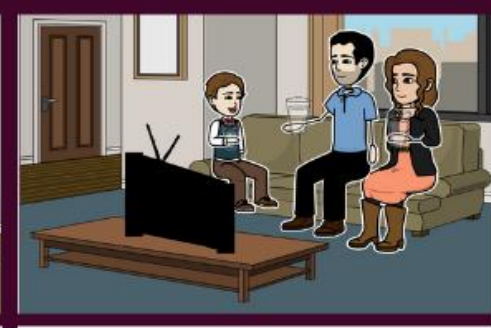

\section{ESCENA 5 - PLANO CONJUNTO}

Voz en on del niño: $\mathrm{Mm}$ delicioso ma. Voz en offi:Disfruta más de tu tiempo
ESCENA 3 - PLANO CENITAL DETALLE

Efecto de Sonido: Cuchara removiendo la

chicha morada dentro de la jarra de vidrio

Voz en off: Natural y fácil de preparar

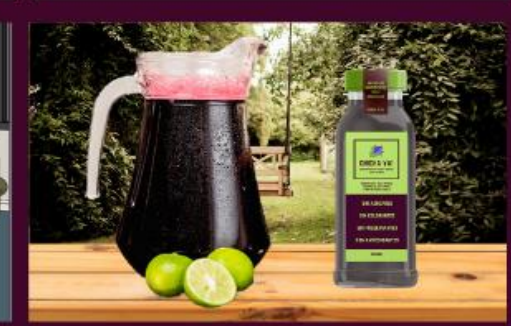

ESCENA 6 - PLANO MEDIO - PACKSHOT

Chicha Ya! $100 \%$ natural y lista en menos de 3 minutos. Disfrútala. 


\subsubsection{Radio}

Complementar las acciones con radio resulta conveniente puesto refuerza el mensaje de la campaña y acerca más nuestro mensaje al público objetivo. Se han elegido dos emisoras, RPP por su gran cobertura a nivel nacional nos proporciona un alcance mayor a otras emisoras y Ritmo Romántica de CRP, radio muy escuchada por el público objetivo.

En cuanto a RPP el precio por segundo asciende a 40 soles, estará en vivo 20 días en total con una frecuencia de 03 veces al día de lunes a viernes. También se contará con un mensaje comercial el cual dirá "Con Chicha Ya! Tienes tu chicha morada 100\% natural en menos de 3 minutos, deliciosa! Según CPI en Lima Metropolitana hay 1,9 millones de radioyentes de RPP semanalmente (p.2). Además según CPI dice que el principal segmento de RPP es el NSE de 26 años a más (p.2). Por ende resulta pertinente la elección de este medio porque el público objetivo se encuentra dentro de este.

En cuanto a Ritmo Romántica según CRP "los que la sintonizan la transmisión son $70 \%$ mujeres y de NSE AB el 15\% y del NSE C el 40\%" (CRP, 2016, p.15). Se estará al aire 20 días en total con una frecuencia de 03 veces al día de lunes a viernes. Según CRP, "Ritmo Romántica semanalmente tiene un alcance de 1.5 millones de mujeres de 17 a 50 años de todos los NSE (p.16). Para ser más específicos con los NSE del público objetivo, el 55\% del total, equivaldría a un alcance de 825,000 mujeres del público objetivo aproximadamente.

Guion del spot radial:

\begin{tabular}{|l|l|}
\hline \multicolumn{1}{|c|}{ Descripción } & \multicolumn{1}{c|}{ Locución } \\
\hline $\begin{array}{l}\text { Se escuchan personas sentándose en una } \\
\text { mesa y empieza la conversación }\end{array}$ & $\begin{array}{l}\text { Hombre 25 años: Uy que rico un lomito } \\
\text { saltado }\end{array}$ \\
\hline Suena efecto de terror & $\begin{array}{l}\text { Mujer 19 años: Oigan, pero no hay jugo en la } \\
\text { mesa, y la chicha tomará más de 01 hora en } \\
\text { hacerse. }\end{array}$ \\
\hline Suena efecto de tranquilidad & $\begin{array}{l}\text { Mujer 40 años: Tranquilos yo tengo la } \\
\text { solución, con el concentrado de Chicha Ya! } \\
\text { tenemos una chicha morada 100\% natural } \\
\text { en menos de 3 minutos }\end{array}$ \\
\hline
\end{tabular}




\begin{tabular}{|l|l|}
\hline $\begin{array}{l}\text { Suena el líquido vertiéndose en una jarra y el } \\
\text { batir de la mezcla con una cuchara de palo } \\
\text { contra el vidrio }\end{array}$ & $\begin{array}{l}\text { Hombre 25 años: ¿En serio? } \\
\text { Mujer 40 años: Sí, solo agreguemos los } \\
500 \mathrm{ml} \text { de la botella a una jarra con } 2 \text { litros de } \\
\text { agua y listo. }\end{array}$ \\
\hline Sonido de vasos haciendo salud & $\begin{array}{l}\text { Mujer 40 años: Listo, salud familia. } \\
\text { Familia: ¡Salud! }\end{array}$ \\
\hline $\begin{array}{l}\text { Música rock instrumental ligero de tipo } \\
\text { comercial }\end{array}$ & Hombre 45 años: Mm delicioso. \\
\hline Locutor & $\begin{array}{l}\text { Locutor: Chicha Ya! tan natural como tú, } \\
\text { encuéntrala en tus supermercados y } \\
\text { bodegas más cercanos }\end{array}$ \\
\hline
\end{tabular}

\subsubsection{Publicidad Exterior}

Las amas de casa modernas suelen trabajar y están activas todo el día por lo que es usual que transiten por varios puntos de Lima. Para la publicidad exterior se contratará con cinco espacios con mucha afluencia de tráfico. En Lima el primero será en la Javier Prado llegando al Jockey Plaza y el segundo será en la Av. Angamos en Miraflores. En provincias se contará con la presencia de un panel digital de la Av. Porongoche de Arequipa y una valla estática en la Av. Miraflores de Trujillo. Por último, se contará con un espacio de valla estática en la Panamericana Sur a la altura del Sur Chico, ruta que se activa bastante en el verano. El mensaje será simple y contundente para todos los paneles, "Prepara tu chicha $100 \%$ natural en menos de 3 minutos". 


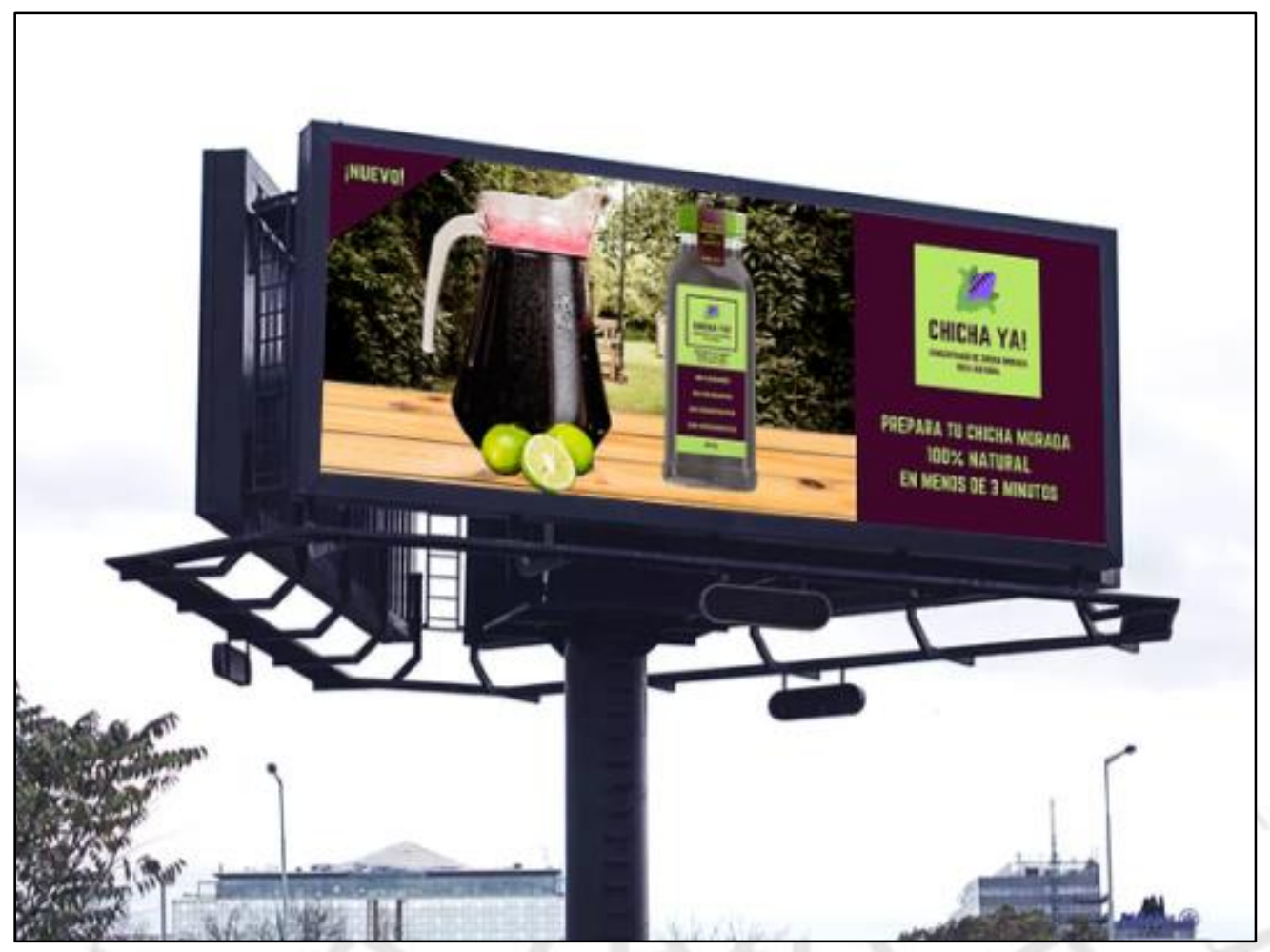

\begin{tabular}{|l|l|l|}
\hline Valla & Lugar & Flujo \\
\hline $01-$ Av. Javier Prado (estático) & Lima & Alto \\
\hline $02-$ Av. Angamos (estático) & Lima & Alto \\
\hline $03-$ Panamericana Sur (estático) & Lima, Sur Chico & Alto \\
\hline $04-$ Av. Porongoche (digital) & Arequipa & Medio-Alto \\
\hline $05-$ Av. Miraflores (estático) & Trujillo & Medio-Alto \\
\hline
\end{tabular}

Fuente: Elaboración Propia

\subsubsection{Publirreportaje}

Se lanzará un publirreportaje sobre Chicha Ya! y se tocará el tema de los beneficios del maíz morado y la proveniencia de sus insumos 100\% peruanos. El objetivo es que pueda haber un acercamiento al consumidor de tipo informativo con la finalidad de que se animen a probar el producto y a disfrutar de los múltiples beneficios que brinda el producto para el bienestar físico y mental de sus consumidores.

Este se publicará en la revista Viú de El Comercio y será una doble página, en específico la segunda doble página de la revista, esta elección es para poder abarcar más información y no quedar tan relegados en lo que es la composición 
de la revista. Según lo visto en el brochure digital de Eco Media, esta es una revista de gran alcance para los NSE AB con un 64\% y algunos del C con un $30 \%$ de la repartición de lectoría la cual asciende a 214,705 personas en promedio, así lo indican los datos del estudio MRP Estudio de Lectoría de Diarios y Revistas en Lima Metropolitana: Setiembre 2014_Agosto 2015 (Eco Media, 2016, p.38)

\subsubsection{Publicidad Impresa}

Se comprará 01 espacio de una página por cada revista de Asia Sur para tener presencia en tres de sus ediciones de verano que se reparten en todo el Sur Chico y Asia. El aviso será de 01 página y tendrá como mensajes "Elabora tu chicha morada $100 \%$ natural en menos de 3 minutos" como gancho para la compra y el mensaje de "Disponible ya en supermercados" para que el consumidor sepa que es un producto el cual lo va a encontrar a donde vaya. Esta acción nos acercará más al NSE A y B debido a la naturaleza de los puntos de distribución. Según Grupo AS, la lectoría promedio según cálculos sería de 45,000 personas debido a que se reparte en 9000 hogares y hay un aproximado de 5 personas por hogar (p.16).

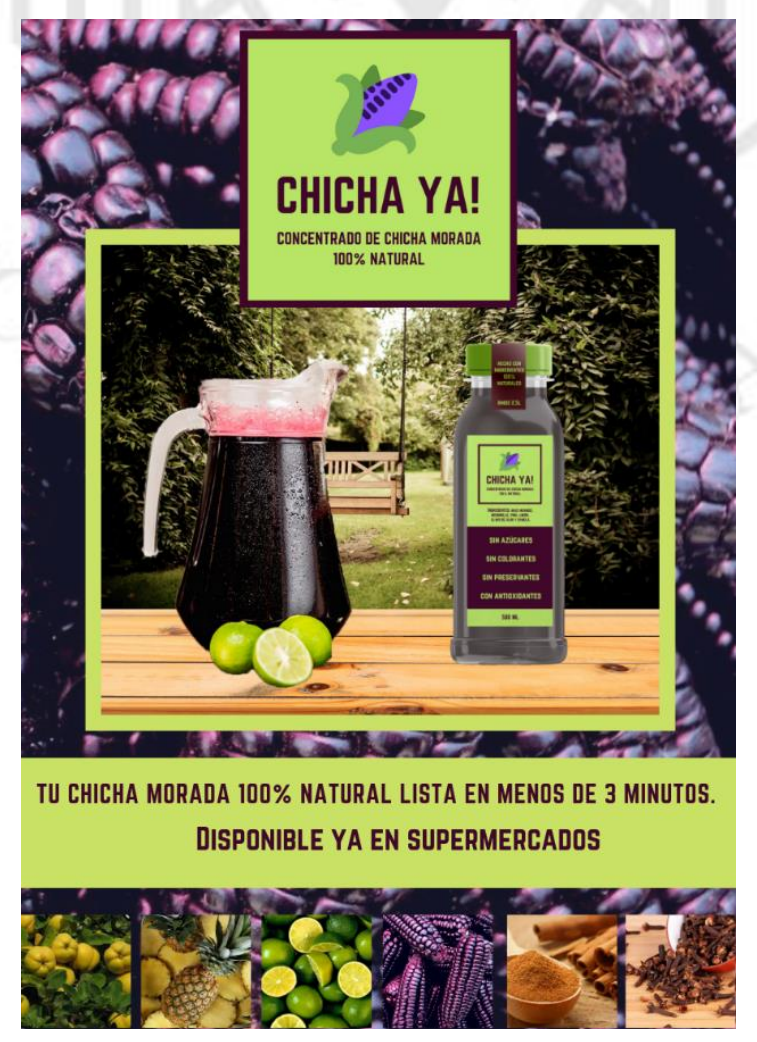




\subsection{Medios Digitales}

\subsubsection{Redes Sociales}

Para incursionar en los medios digitales "Chicha Ya!" contará con Facebook, Instagram y canal de YouTube.

El propósito del Facebook será el de mantenernos relevantes para los consumidores, se contarán con tres tipos de post.

\begin{tabular}{|l|l|}
\hline Tipo de Post & Ejemplo de Comunicación (copy) \\
\hline Racional & $\begin{array}{l}\text { ¿Sabías que puedes hacer una chicha morada 100\% natural en menos de } \\
\text { 3 minutos? ¡Con el concentrado Chicha Ya, es posible! \#ChichaMorada } \\
\text { \#ChichaYa \#100\%Natural }\end{array}$ \\
\hline $\begin{array}{l}\text { Dinámico - } \\
\text { Concurso }\end{array}$ & $\begin{array}{l}\text { Varias personas tienen una manera peculiar de disfrutar la chicha morada. } \\
\text { Y tersonas quienes disfrutas Chicha Ya? Etiqueta en los comentarios a dos } \\
\text { betellas de Chicha Ya. Términos y Condiciones en: (link) \#ChichaMorada } \\
\text { \#ChichaYa \#100\%Natural }\end{array}$ \\
\hline Coyuntural & $\begin{array}{l}\text { Hoy sábado 18 nuestra querida capital Lima cumple 485 años, celebremos } \\
\text { este día con una rica chicha morada. ¡Chicha Ya, tan natural como tú! } \\
\text { \#AniversarioDeLima \#ChichaMorada \#ChichaYa \#100\%Natural }\end{array}$ \\
\hline
\end{tabular}

Fuente: Elaboración Propia 


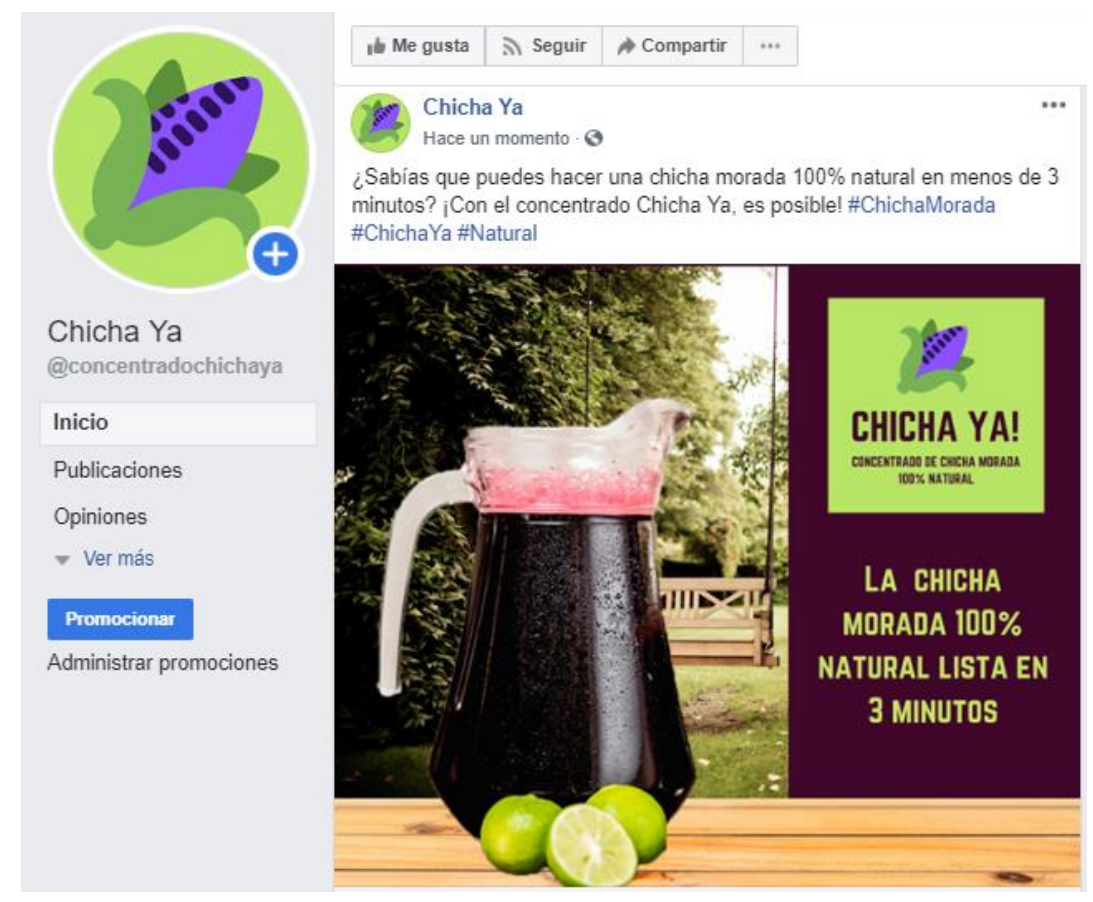

Enlace del fan Page: fb.me/concentradochichaya

El tipo de pauta que se implementará en Facebook tendrá como objetivo la compra de likes a la página, alcance e interacciones en los posts, así como la visualización del spot. Se busca reforzar bastante estos cuatro para poder crear la base de lo que sería la comunidad digital de Chicha Ya.

En cuanto a la segmentación será mujeres de 25 a 50 años con intereses y ciudades clave como datos demográficos, teniendo así un alcance potencial de 4,6 millones de personas.
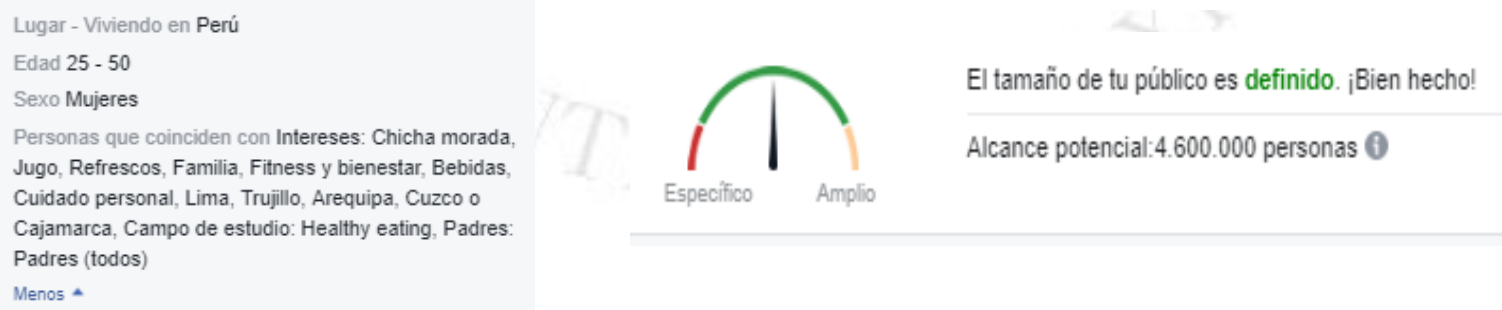

El propósito de Instagram será el de compartir videos en vivo de la marca y de comunicar los beneficios del producto. Instagram es una red que está ganando adeptos muy rápidamente en Perú y muchas influencers del público objetivo están usando la red como parte de sus canales de comunicación. En esta ocasión no se usarán influencers para el lanzamiento, sino se usarán para 
tácticas más adelante en la etapa de mantenimiento. La razón es que el público objetivo aún no se ha adaptado muy bien a esa red social.

El propósito de YouTube será el de una videoteca donde se guarden y se reutilicen los videos de la marca. El spot que saldrá en TV se replicará en YouTube mediante publicidad In-Stream y será crossdevice.

Cabe rescatar que estos tres medios coexistirán y seguirán un orden de publicación como lo indicado en los cuadros del anexo en la página 47.

\subsubsection{Página Web}

Hoy en día tener una página web otorga más credibilidad a las marcas, por ello Chicha Ya! tendrá su propio landing, página web. El objetivo de su creación no solo es tener visibilidad sino usarla para utilizar la metodología de inbound marketing. Lo que se quiere lograr es que los consumidores se enteren del producto y puedan conocer más sobre la marca en la web la cual ha sido creada con Wix.

El sitio cuenta con dos secciones, inicio y blog. En el inicio se encuentra un saludo de la marca que se compone en su propósito de responsabilidad social y un refuerzo de lo natural y lo conveniente que es. Luego están en el medio cada uno de los ingredientes con una pequeña reseña introductoria. Finalmente se encuentra la sección de contacto, el mapa de ubicación y también cuenta con su propio chatbot para responder consultas de manera más rápida y cercana. En la parte del blog se subirán notas de interés para la marca como por ejemplo propiedades del maíz morado, usos del producto, entre otros. 


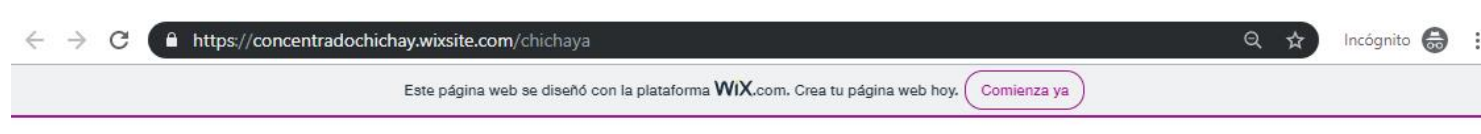

СHICHA YA!
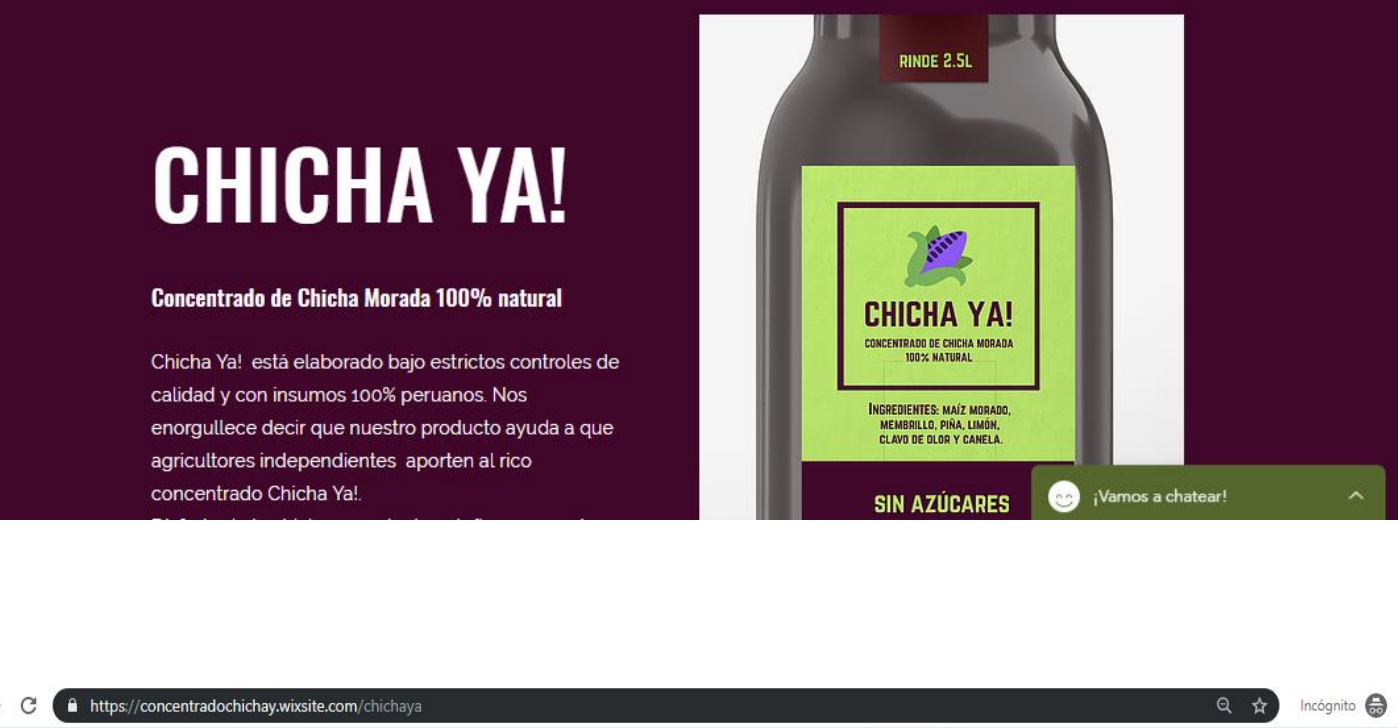

Este página web se diseńo con la plataforma WIX.com. Crea tu página web hoy. Comienza ya

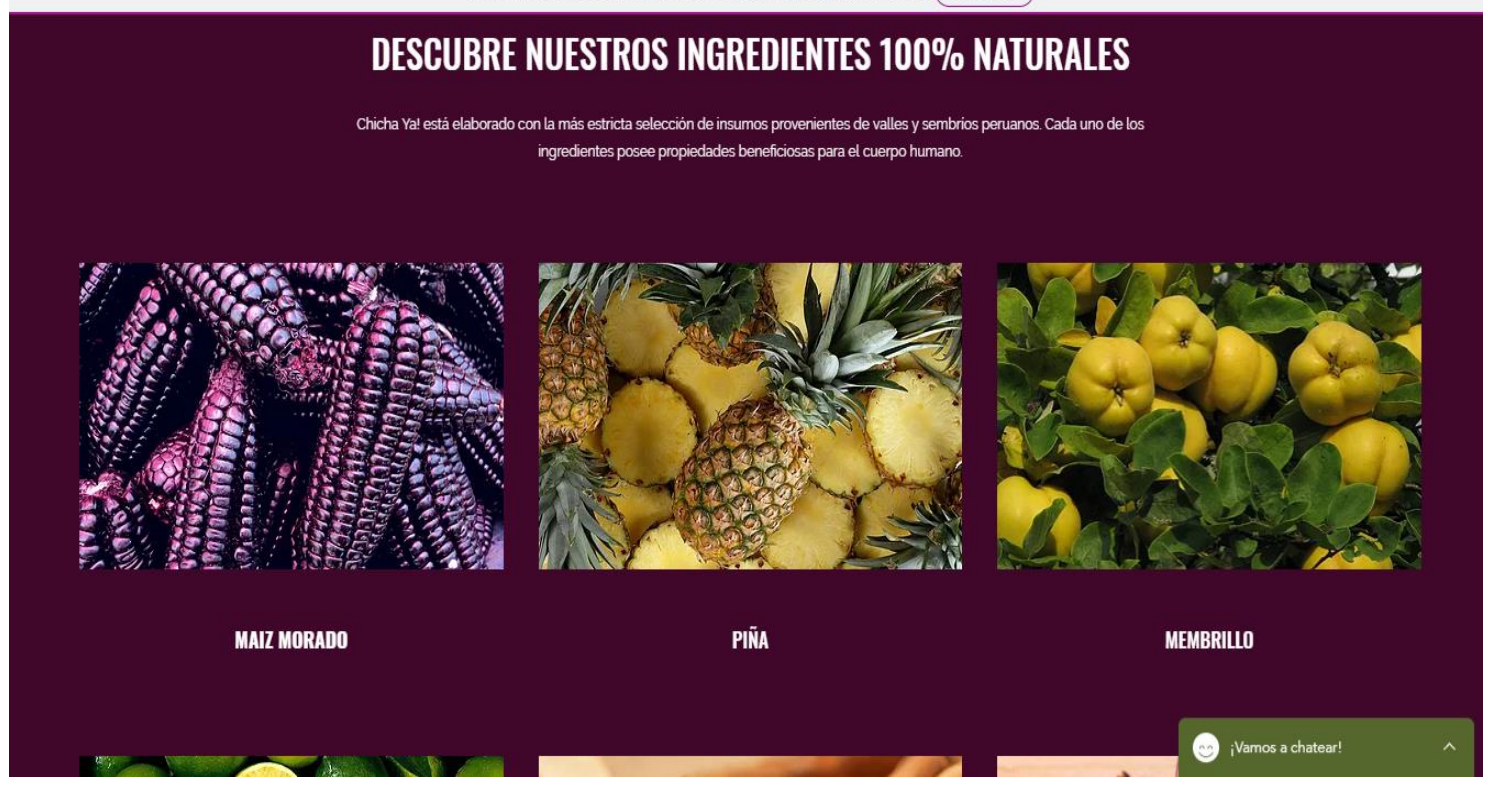

Enlace del sitio web: https://concentradochichay.wixsite.com/chichaya

\subsubsection{Google AdWords}

Se utilizará la publicidad en el motor de búsqueda de Google. El objetivo de esta acción es complementar las acciones de medios tradicionales y digitales para 
tener una presencia 360 en lo que respecta a la campaña. Estos avisos estarán activos por los 3 meses de la campaña y el objetivo de estos será por impresiones en el primer mes, en el segundo mes costo por click y en el tercer mes se retornara a la inversión por impresiones. Se ha elegido la publicidad por impresiones puesto lo que se busca es que el producto entre al top of mind de los consumidores y las impresiones más frecuencia resultan efectivas para este tipo de objetivo.

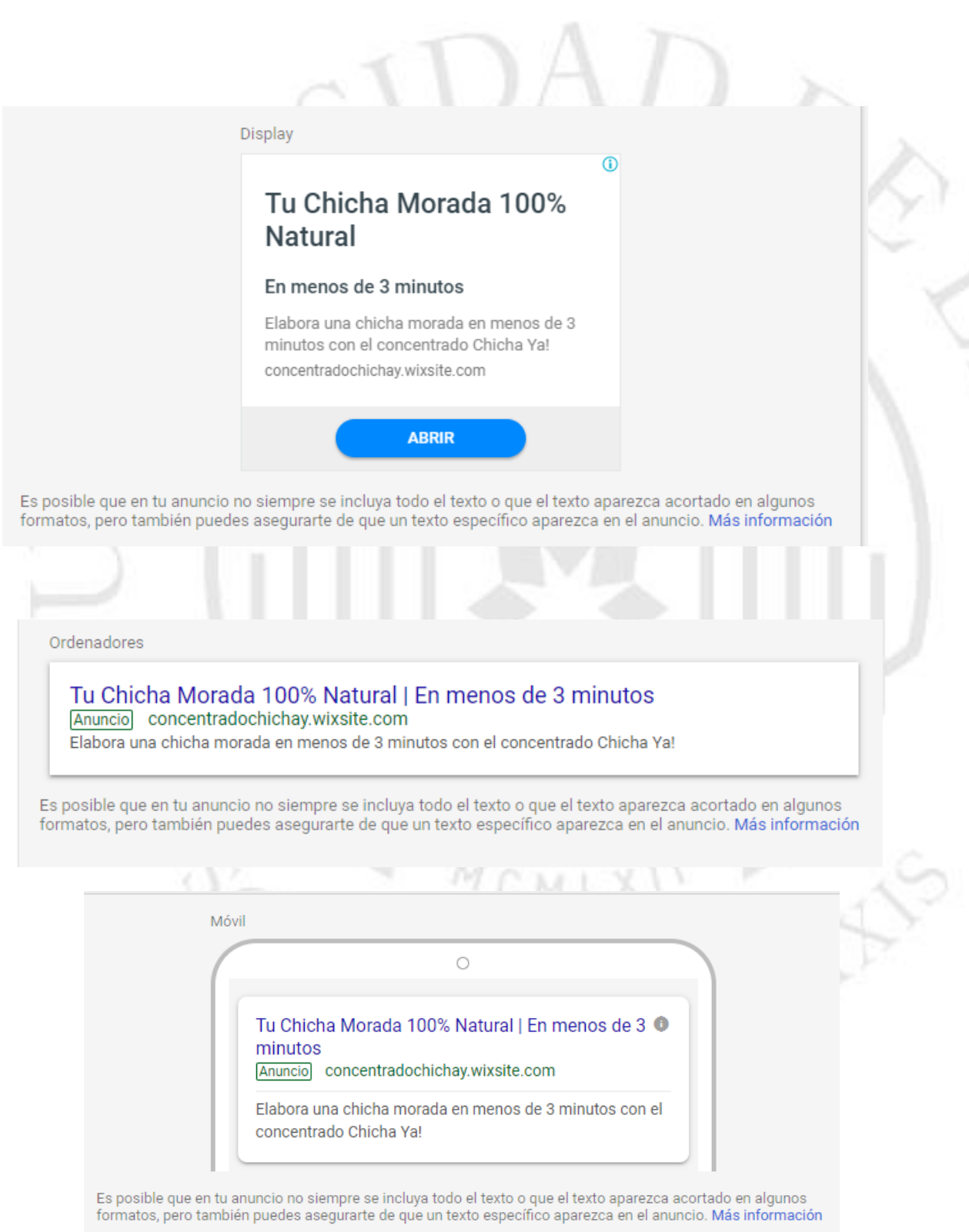




\subsubsection{Cuadro de KPIs para medios digitales:}

\begin{tabular}{|c|c|c|c|c|c|c|c|c|}
\hline Objetivo & Medio & Sección & Segmentación & Formato & KPI & $\begin{array}{l}\text { Costo } \\
\text { unitario }\end{array}$ & $\begin{array}{l}\text { Costo } \\
\text { total }\end{array}$ & $\begin{array}{l}\text { Impacto } \\
\text { Total en } 3 \\
\text { meses }\end{array}$ \\
\hline Compra de Likes & $\begin{array}{l}\text { Facebook/ } \\
\text { Instagram }\end{array}$ & $\begin{array}{l}\text { Cross } \\
\text { Device }\end{array}$ & $\begin{array}{l}\text { Demográfico/ } \\
\text { Intereses }\end{array}$ & PPA & CPA & $\$ 0.2$ & $\begin{array}{l}3000 \\
(2000 \\
F B \quad+ \\
1000 \\
\text { IG) }\end{array}$ & $\begin{array}{l}15000 \text { likes } \\
\text { a la página } \\
\text { (FB). } \\
10,000 \\
\text { followers } \\
\text { (IG) }\end{array}$ \\
\hline Alcance & $\begin{array}{l}\text { Facebook/ } \\
\text { Instagram }\end{array}$ & $\begin{array}{l}\text { Cross } \\
\text { Device }\end{array}$ & $\begin{array}{l}\text { Demográfico/ } \\
\text { Intereses }\end{array}$ & PPA & CPM & $\$ 0.6$ & $\begin{array}{l}3000 \\
(2000 \\
\mathrm{FB} \\
1000 \\
\text { IG) }\end{array}+$ & $\begin{array}{l}3,3 \text { millones } \\
\text { de } \\
\text { impresiones } \\
\text { (FB). } 1,6 \\
\text { millones en } \\
\text { (IG) }\end{array}$ \\
\hline Conversiones & $\begin{array}{l}\text { Facebook/ } \\
\text { Instagram }\end{array}$ & $\begin{array}{l}\text { Cross } \\
\text { Device }\end{array}$ & $\begin{array}{l}\text { Demográfico/ } \\
\text { Intereses }\end{array}$ & PPL & CPC & $\begin{array}{l}\$ 0.05 \\
\$ 0.05\end{array}$ & $\begin{array}{l}3000 \\
(2000 \\
\mathrm{FB} \\
1000 \\
\text { IG) }\end{array}+$ & $\begin{array}{l}40 \text { mil clics } \\
\text { en anuncios } \\
\text { (FB) } 20 \text { mil } \\
\text { clics en } \\
\text { anuncios } \\
\text { (IG) }\end{array}$ \\
\hline $\begin{array}{l}\text { Reproducciones de } \\
\text { Spot }\end{array}$ & Facebook & $\begin{array}{l}\text { Cross } \\
\text { Device }\end{array}$ & $\begin{array}{l}\text { Demográfico/ } \\
\text { Intereses }\end{array}$ & Video Ad & CPV & $\$ 0.03$ & $\$ 30,000$ & $\begin{array}{l}1 \text { millón de } \\
\text { vistas }\end{array}$ \\
\hline $\begin{array}{l}\text { Reproducciones de } \\
\text { Spot }\end{array}$ & YouTube & $\begin{array}{l}\text { Cross } \\
\text { Device }\end{array}$ & $\begin{array}{l}\text { Demográfico/ } \\
\text { Intereses }\end{array}$ & $\begin{array}{l}\text { Video In- } \\
\text { Stream }\end{array}$ & CPV & $\$ 0.03$ & $\$ 40,000$ & $\begin{array}{l}1,3 \text { millones } \\
\text { de vistas }\end{array}$ \\
\hline $\begin{array}{l}\text { Impresiones + Visitas } \\
\text { a la web }\end{array}$ & AdWords & $\begin{array}{l}\text { Cross } \\
\text { Device }\end{array}$ & $\begin{array}{l}\text { Demográfico/ } \\
\text { Intereses }\end{array}$ & $\begin{array}{l}\text { Display } \\
+ \text { Texto }\end{array}$ & $\begin{array}{l}\text { CPM } \\
\text { CPC }\end{array}$ & $\begin{array}{l}\$ 5 \\
\$ 2\end{array}$ & $\begin{array}{l}\$ 20,000 \\
\$ 10,000\end{array}$ & $\begin{array}{l}6 \text { millones } \\
\text { de } \\
\text { impresiones } \\
\text { y } 5 \text { mil clics } \\
\text { en anuncios }\end{array}$ \\
\hline
\end{tabular}




\subsection{Medios Alternativos}

\subsubsection{Activación en Boulevard de Asia}

¿Qué se quiere lograr?

Llamar la atención de los transeúntes, reforzar el mensaje de que el producto está elaborado con insumos $100 \%$ naturales y que su uso para hacer la bebida de chicha morada toma menos de tres minutos.

¿Cómo se logrará?

A través de una activación en el Boulevard de Asia sur, la cual consistirá en lo siguiente:

1. En el espacio otorgado estará una botella de Chicha Ya! transparente de $2 \mathrm{~m}$ de altura y $50 \mathrm{~cm}$ de circunferencia, esta botella contendrá los ingredientes del producto los cuales son maíz morado, piña, membrillo, limones, canela y clavos de olor.

2. Al costado de la botella habrá un roll que dirá lo siguiente "Lo ves, lo contiene. Prepara tu chicha $100 \%$ natural en menos de 3 minutos con Chicha Ya!"

3. Al otro costado de la botella habrá un pequeño módulo de $1 \times 1$ con dos degustadoras quienes prepararán en tiempo real la chicha morada y la darán a degustar a los transeúntes. También repartirán volantes que se pueden usar como cupones de descuento de 1 sol y así seguir la línea de reciclaje pactada con Súper Mercados Peruanos.

\subsubsection{Volanteo y degustaciones en Sur Chico y Ancón}

Se repartirán volantes y botellas de Chicha Ya! en la entrada de Punta Hermosa, San Bartolo, Punta Negra, Pulpos y Ancón a las personas. Esta acción se sustenta debido a que muchas personas alquilan casa en verano y repartir el producto es oportuno puesto lo pueden elaborar en sus casas en pocos minutos. 


\subsubsection{Degustaciones en Punto de Venta}

Las degustaciones en punto de venta serán con Super Mercados Peruanos con sus tiendas Plaza Vea, la cual está destinada a un NSE B y $C$ y Vivanda el cual tiene consumidores en su mayoría del NSE A y B. También estará presente la marca en los supermercados Tottus los cuales se acercan de manera más integral al publico objetivo al tener tiendas con públicos de los NSE A, B y C.

Para esta acción se contará con visicooler y un stand simple donde la degustadora dará a probar el producto a las personas interesadas, además de hacer también presentaciones de preparación en vivo. Adicionalmente, repartirá un volante $A 5$ donde estará la información del producto y que servirá también de cupón de descuento, de esa manera los colaboradores de Super Mercados Peruanos y Tottus a nivel interno nos pueden devolver los volantes para llevarlos a una planta de reciclaje. 


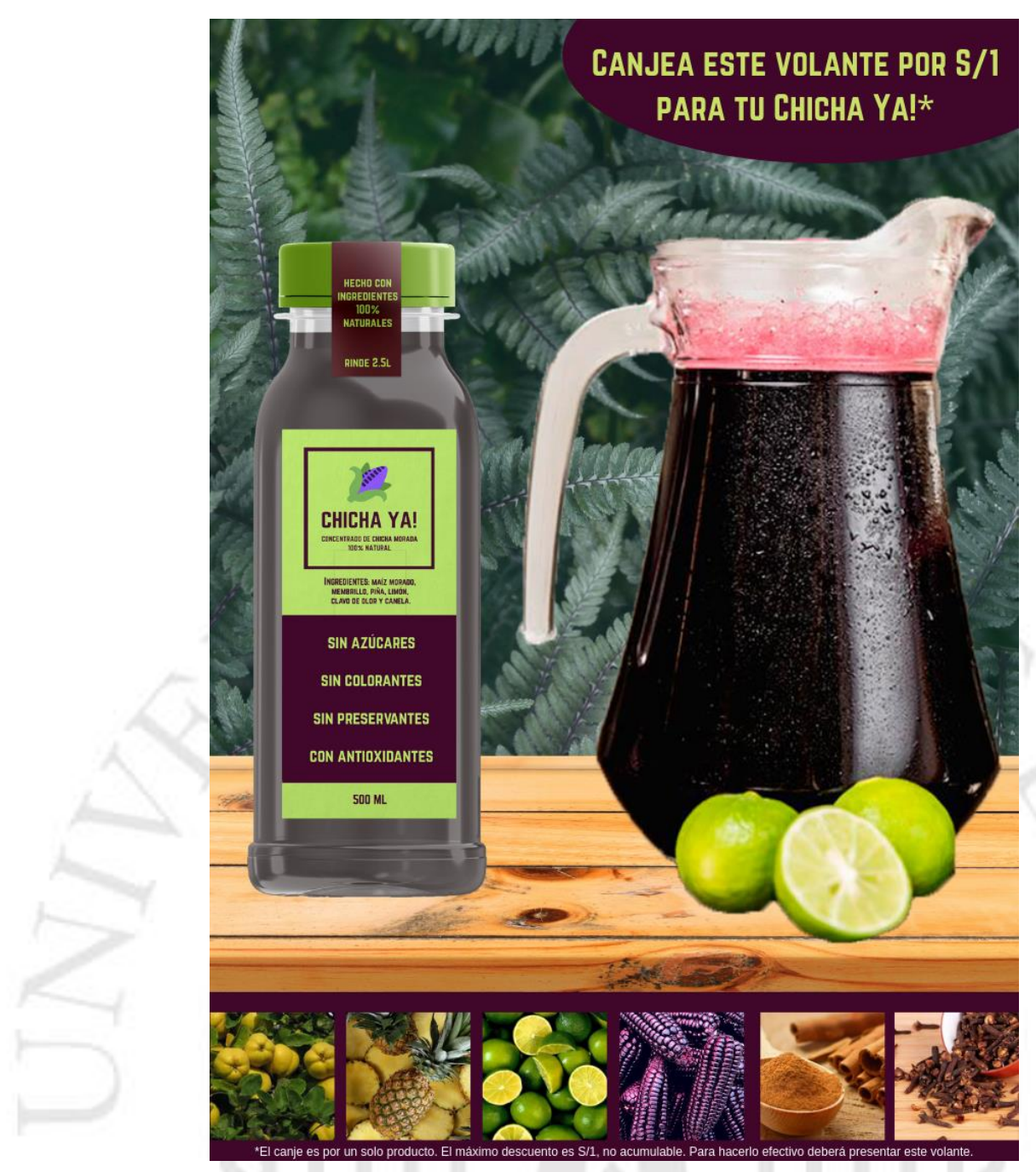

\subsection{Presupuesto de Medios}

En el cuadro de abajo se podrá ver la inversión por medio de comunicación, se ha equilibrado la campaña entre lo tradicional y lo digital y alternativo pero destinando un mayor porcentaje a lo que respectan los medios ATL por la naturaleza de las tarifas de los medios que la comprenden. La inversión en digital es alta frente a otras marcas puesto se quiere generar frecuencia y ganar el público objetivo para formar una comunidad. Se ha invertido en total $\$ 56900$ en gastos de producción, fees de agencia y diseño de marca. Además se han invertido en total $\$ 437563$ en medios. Sumando así $\$ 494463$, presupuesto dentro de los $\$ 500000$ ofrecidos para la campaña. Se espera un ROI de 1.5 a 1.8 .

\begin{tabular}{|l|r|}
\hline Detalle & $\begin{array}{l}\text { Precio en US\$+ } \\
\text { IGV }\end{array}$ \\
\hline Identidad de la Marca \& Fees & \\
\hline $\begin{array}{l}\text { Diseño de identidad gráfica de la marca: Naming, Logo, Packaging y } \\
\text { etiquetado con una Agencia Top especializada en branding }\end{array}$ & 6000 \\
\hline Fee Integral de la agencia de publicidad y diseño por 3 meses & 12000 \\
\hline
\end{tabular}




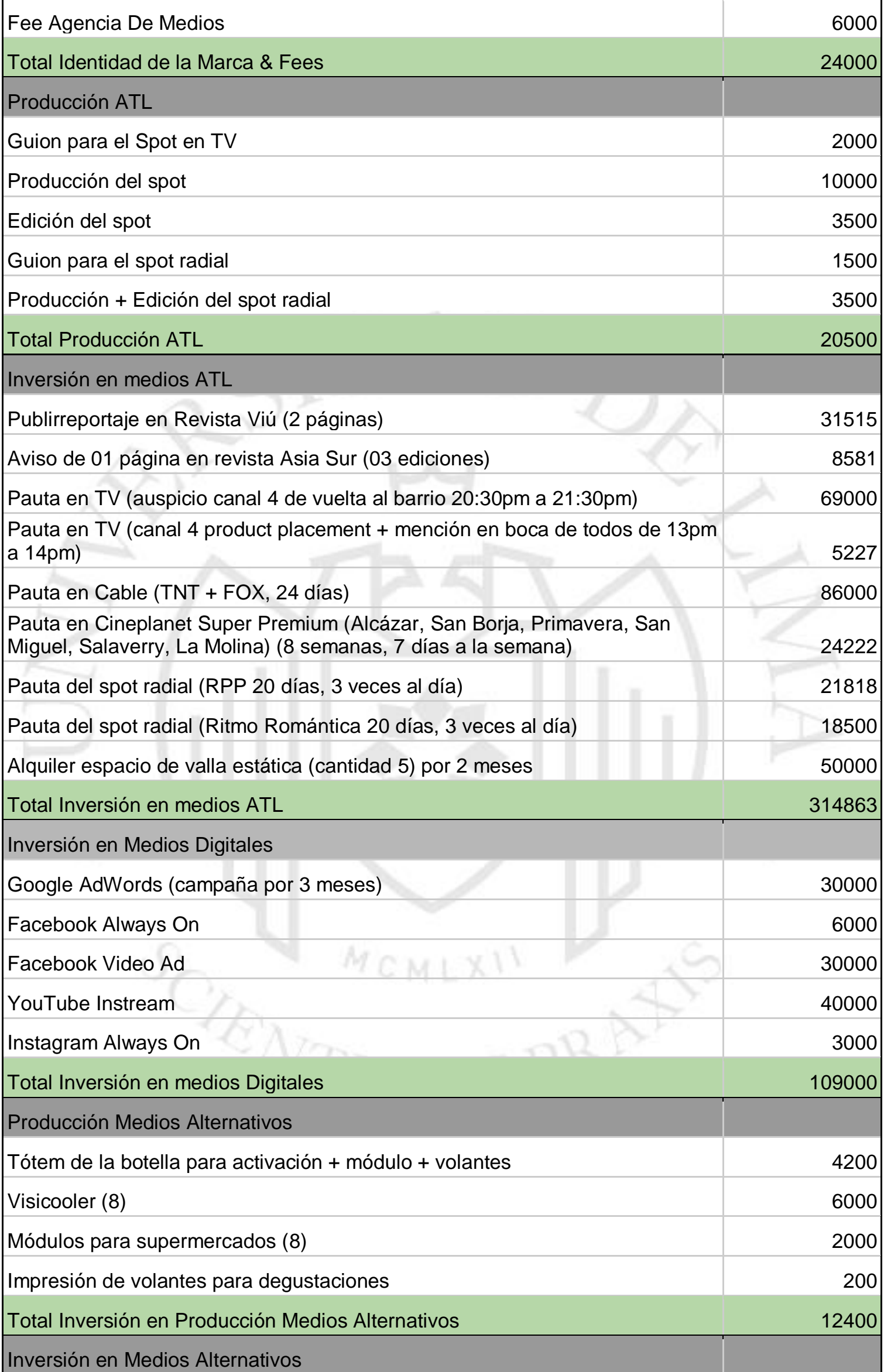




\begin{tabular}{|l|r|}
\hline Espacio para activación super premium en el Boulevard de Asia por 2 días + \\
\hline IGV & 2950 \\
\hline Espacio en Plaza Vea y Vivanda & 3600 \\
\hline Espacio en Tottus & 3300 \\
\hline Degustadoras (cantidad 8, dólares por cada una al día 20, total de días 24) & 3850 \\
\hline Total Inversión en Medios Alternativos & 13700 \\
\hline TOTAL GENERAL & 494463 \\
\hline
\end{tabular}

Para tener una visión más clara del presupuesto debajo están dos cuadros con la distribución porcentual de cada uno, en el de producción se ha divido a grandes rasgos por agencias sumando 43\% (en morado), producción de spot audiovisual sumando $27 \%$ (en celeste), spot radial sumando $9 \%$ (en verde) y compra de insumos para llevar acabo las actividades de medios alternativos sumando $21 \%$ (en amarillo). La inversión de esta parte asciende a $\$ 56900$.

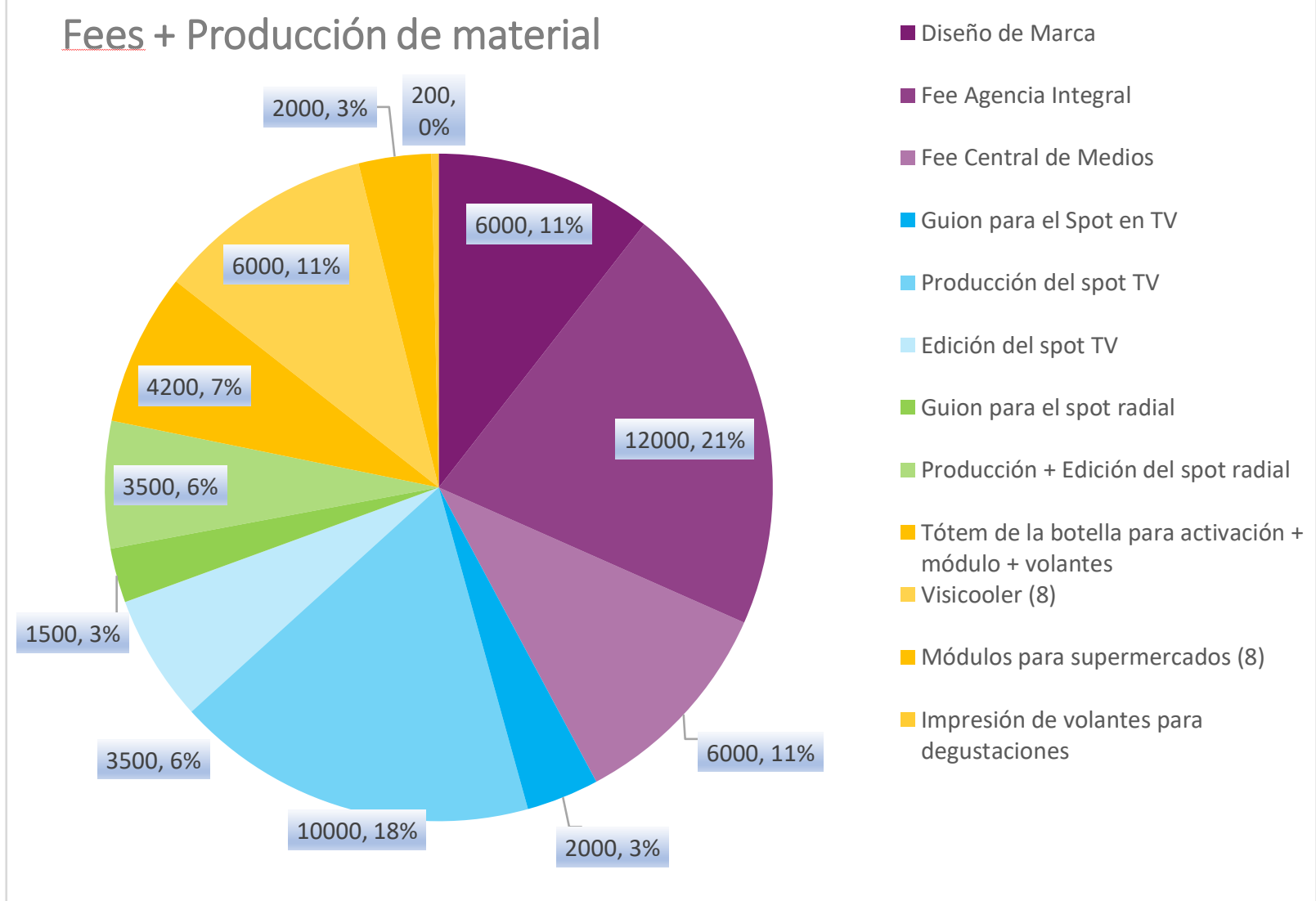

Fuente: Elaboración Propia 
En cuanto al de distribución de inversión por medios se ha divido a grandes rasgos por medios ATL sumando $72 \%$ (en morado), medios digitales sumando $24 \%$ (en rojo) y medios alternativos sumando 4\% (en amarillo). La inversión de esta parte asciende a $\$ 437563$.

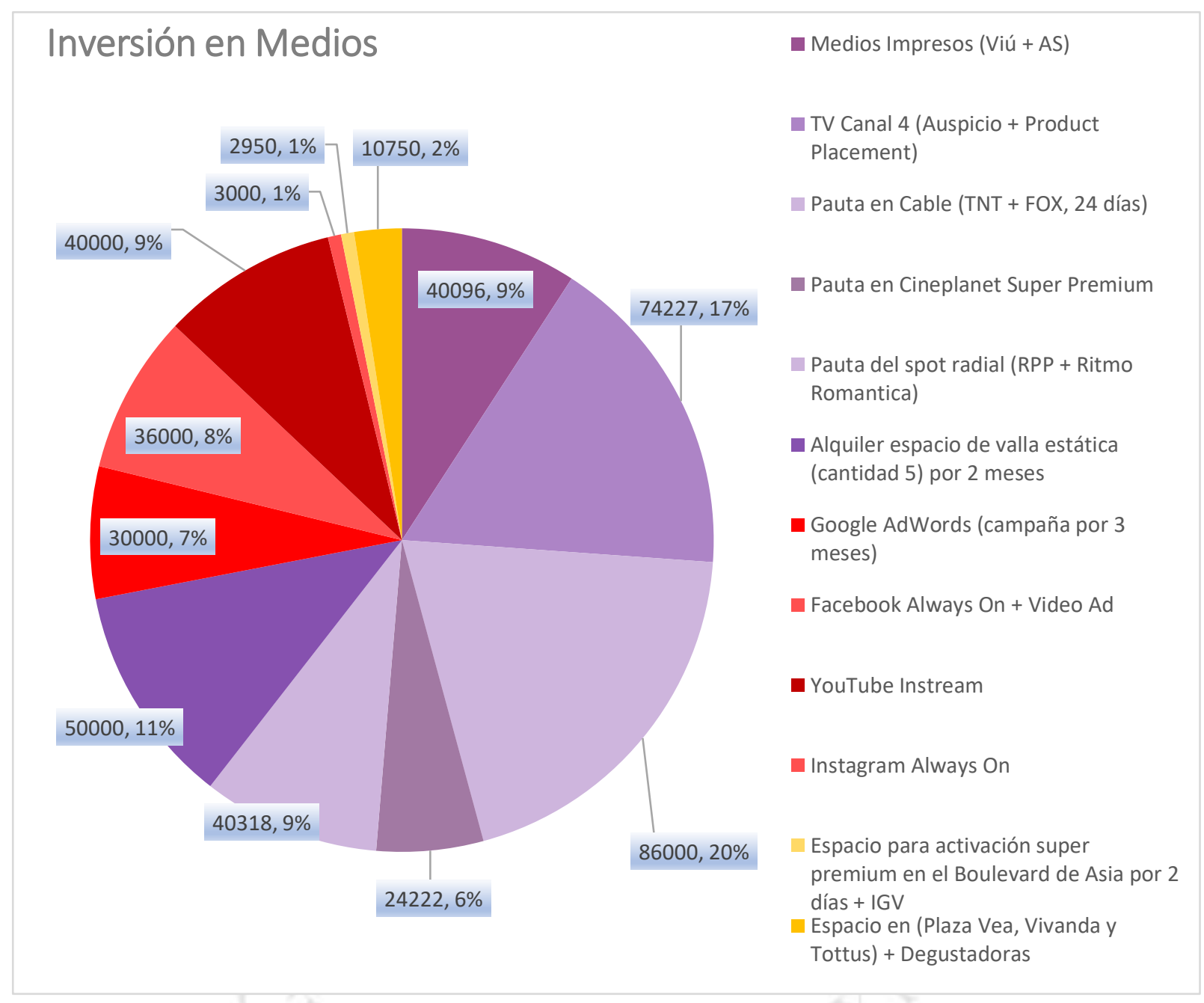

Fuente: Elaboración Propia

\subsection{Distribución de Medios}

Para la correcta visión de la campaña de lanzamiento se han plasmado los días en los que tendrá presencia cada medio. Se empezará fuerte con presencia multicanal y se mantendrá hasta el final con pauta digital, publicidad exterior y degustaciones en puntos de venta. 


\begin{tabular}{|c|c|c|c|c|c|c|c|c|c|c|c|c|c|c|c|c|c|c|c|c|c|c|c|c|}
\hline MEDIO & & & & & & & & & & & & ENE & RO & & & & & & & & & & & \\
\hline DIA & 8 & 9 & 10 & 11 & 12 & 13 & 14 & 15 & 16 & 17 & 18 & \begin{tabular}{|l|}
19 \\
\end{tabular} & 20 & 21 & 22 & 23 & 24 & 25 & 26 & 27 & 28 & 29 & 30 & 31 \\
\hline Auspicio canal 4 & & & & & & & & & & & & & & & & & & & & & & & & \\
\hline Product Placement canal 4 & & & & & & & & & & & & & & & & & & & & & & & & \\
\hline TNT & & & & & & & & & & & & & & & & & & & & & & & & \\
\hline FOX & & & & & & & & & & & & & & & & & & & & & & & & \\
\hline Cine Planet & & & & & & & & & & & & & & & & & & & & & & & & \\
\hline Spot radial RPP & & & & & & & & & & & & & & & & & & & & & & & & \\
\hline Sport Radial Ritmo Romantica & & & & & & & & & & & & & & & & & & & & & & & & \\
\hline Publireportaje Viú & & & & & & & & & & & & & & & & & & & & & & & & \\
\hline Publicidad en Revista Asia Sur & & & & & & & & & & & & & & & & & & & & & & & & \\
\hline Vallas (05) & & & & & & & & & & & & & & & & & & & & & & & & \\
\hline Google Adwords & & & & & & & & & & & & & & & & & & & & & & & & \\
\hline Facebook & & & & & & & & & & & & & & & & & & & & & & & & \\
\hline Facebook Instream & & & & & & & & & & & & & & & & & & & & & & & & \\
\hline Instagram & & & & & & & & & & & & & & & & & & & & & & & & \\
\hline Youtube & & & & & & & & & & & & & & & & & & & & & & & & \\
\hline Youtube InStream & & & & & & & & & & & & & & & & & & & & & & & & \\
\hline Activación Asia & & & & & & & & & & & & & & & & & & & & & & & & \\
\hline Activación Sur Chico y Ancón & & & & & & & & & & & & & & & & & & & & & & & & \\
\hline Degustaciones Punto de Venta & & & & & & & & & & & & & & & & & & & & & & & & \\
\hline
\end{tabular}

Fuente: Elaboración Propia

\begin{tabular}{|c|c|c|c|c|c|c|c|c|c|c|c|c|c|c|c|c|c|c|c|c|c|c|c|c|c|c|c|c|c|}
\hline MEDIO & \multicolumn{29}{|c|}{ FEBRERO } \\
\hline DIA & 1 & 2 & 3 & 4 & 5 & 6 & 7 & 8 & 9 & 10 & 11 & 12 & 13 & 14 & 15 & 16 & 17 & 18 & 19 & 20 & 21 & 22 & 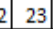 & 24 & 25 & 26 & 27 & 28 & 29 \\
\hline \multicolumn{30}{|l|}{ Auspicio canal 4} \\
\hline \multicolumn{30}{|l|}{ Product Placement canal 4} \\
\hline \multicolumn{30}{|l|}{ TNT } \\
\hline \multicolumn{30}{|l|}{ FOX } \\
\hline \multicolumn{30}{|l|}{ Cine Planet } \\
\hline \multicolumn{30}{|l|}{ Spot radial RPP } \\
\hline \multicolumn{30}{|l|}{ Sport Radial Ritmo Romantica } \\
\hline \multicolumn{30}{|l|}{ Publireportaje Viú } \\
\hline \multicolumn{30}{|l|}{ Publicidad en Revista Asia Sur } \\
\hline \multicolumn{30}{|l|}{ Vallas (05) } \\
\hline \multicolumn{30}{|l|}{ Google Adwords } \\
\hline \multicolumn{30}{|l|}{ Facebook } \\
\hline \multicolumn{30}{|l|}{ Facebook Instream } \\
\hline \multicolumn{30}{|l|}{ Instagram } \\
\hline \multicolumn{30}{|l|}{ Youtube } \\
\hline \multicolumn{30}{|l|}{ Youtube InStream } \\
\hline \multicolumn{30}{|l|}{ Activación Asia } \\
\hline \multicolumn{30}{|l|}{ Activación Sur Chico y Ancón } \\
\hline Degustaciones Punto de Venta & & & & & & & & & & & & & & & & & & & & & & & & & & & & & \\
\hline
\end{tabular}

Degustaciones Punto de Venta

Fuente: Elaboración Propia

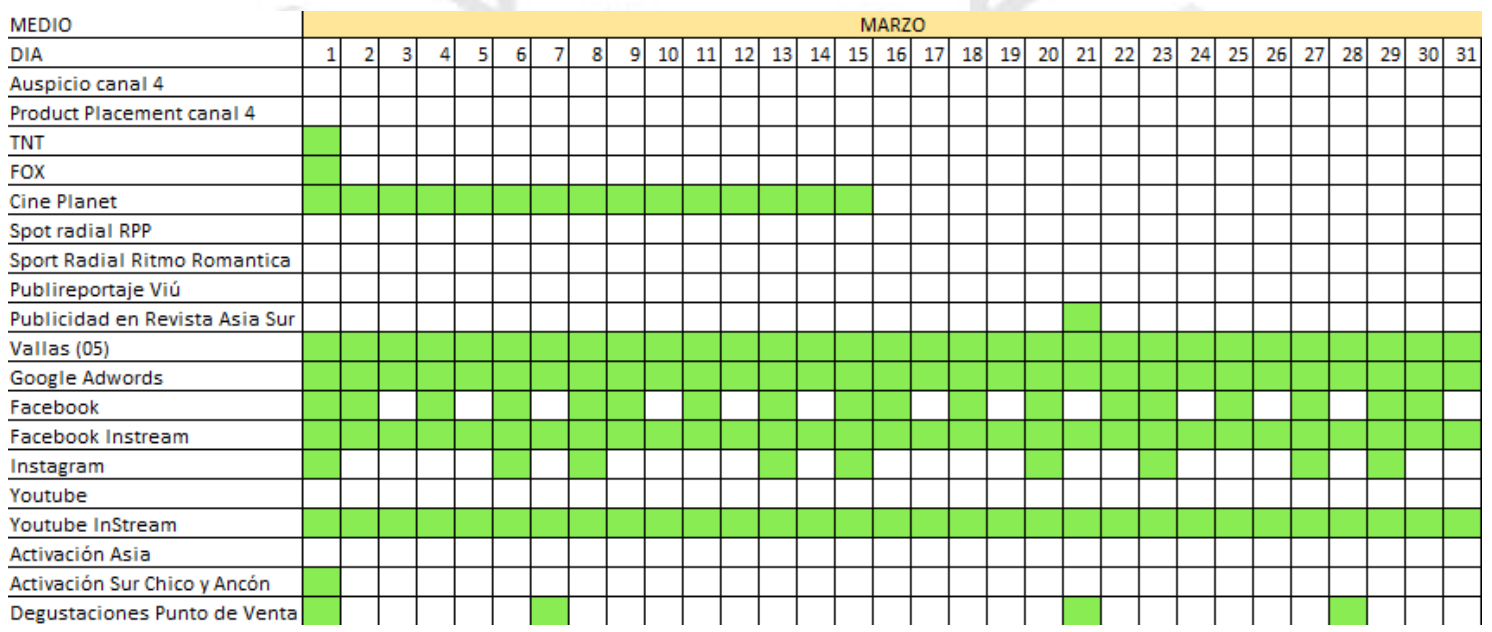

Fuente: Elaboración Propia 


\section{RECOMENDACIONES}

Se recomienda que la marca solidifique su presencia en medios digitales y no los deje de lado puesto son un canal de comunicación muy importante puesto nos acercan al público objetivo y transforman la comunicación en horizontal. Facebook se ha convertido en una plataforma que permite al usuario comunicarse con las marcas, un usuario puede preguntar muchas cosas a la marca, como por ejemplo: Vivo en Miraflores, ¿tendrán el producto en el Plaza Vea de la Av. Arequipa? o también hay usuarios curiosos que nos pueden preguntar ¿Qué tipo de piña contiene su producto? Con esto reafirmo que mantener Facebook será de gran ayuda para la marca. Así mismo se sugiere no dejar de lado la página web y construir material en el blog de este. En cuanto a medios tradicionales se recomienda por todo el 2020 tener una campaña de mantenimiento con vallas y PR3.0 para que la marca no pierda la relevancia que se ha querido obtener con su campaña de lanzamiento.

En cuanto a nivel de empresa, se sugiere que para aprovechar la oportunidad del mercado que está virando hacia un consumo de productos naturales como es el concentrado de chicha morada "Chicha Ya!" el cual se presta muy bien para la coyuntura. De ser aceptado por el público objetivo se puede lanzar una línea de más concentrados de jugos bajo la marca paraguas "Ya!", como por ejemplo concentrado de jugo de manzana "Manzana Ya!", concentrado de maracuyá "Maracu Ya!" entre otros productos que pueden agregar valor a la nueva marca paraguas.

Por último, el peruano gusta mucho de su gastronomía por lo que se recomienda armar un plan de marketing internacional para exportar el producto a países con colonias grandes de peruanos como lo son: Estados Unidos, Argentina y España, por mencionar algunos. 


\section{REFERENCIAS}

Arellano. Las Modernas. Mayo, 2019, de Arellano Sitio web: https://www.arellano.pe/los-seis-estilos-de-vida/las-modernas/

CPI. (2017). Audiencias radiales 2016 Resumen anual. junio 8, 2019, de CPI Sitio web: https://cpi.pe/images/upload/paginaweb/archivo/26/mr resumen anual audien cia radial 2016.pdf

CRP. (2016). CRP: Medios y Entretenimiento. Mayo, 2019, de CRP Sitio web: https://www.mom-rsf.org/uploads/tx Ifrogmom/documents/35-205 import.pdf

Diario Correo. (2019). 5 datos sobre el consumo de bebidas de fruta en el Perú. Mayo, 2019, de Diario Correo Sitio web: https://diariocorreo.pe/gastronomia/5datos-sobre-el-consumo-de-bebidas-de-fruta-en-el-peru-872857/

Diario El Comercio. (2019). Octógonos de advertencia / ¿Qué son y por qué serán obligatorios desde el 17 de junio?. Mayo, 2019, de Diario El Comercio Sitio web: $\quad$ https://elcomercio.pe/tecnologia/ciencias/octogonos-advertencia-sirvenseran-obligatorios-junio-noticia-610351

Eco Media. (2016). Media Kit: Tarifario Actualización El Comercio 2016. Mayo, 2019, de Eco Media Sitio web: http://e.gec.pe/67/doc/0/0/7/4/7/747749.pdf

EcuRed. (2018). Maíz morado. Mayo, 2019, de EcuRed Sitio web: https://www.ecured.cu/Ma\%C3\%ADz morado

Euromonitor International. (2019). Concentrates in Peru. Mayo, 2019, de Euromonitor International Sitio web: https://www.euromonitor.com/concentratesin-peru/report

Grupo AS. (2015). Media Kit 2015, 40.

Ipsos. (2017) Medios Tradicionales: Hábitos y actitudes. Lima Metropolitana. Ipsos

Ipsos. (2018) Perfil del ama de casa peruana. Perú Urbano. Ipsos

Raúl Díaz. (2018). Alimentos \& Bebidas: 5 Tendencias en 2018. Mayo, 2019, de Mercado Negro Sitio web: https://www.mercadonegro.pe/alimentos-bebidas-5tendencias-en-2018/ 


\section{ANEXOS}

Ecosistema de redes sociales (grilla de distribución del always-on):
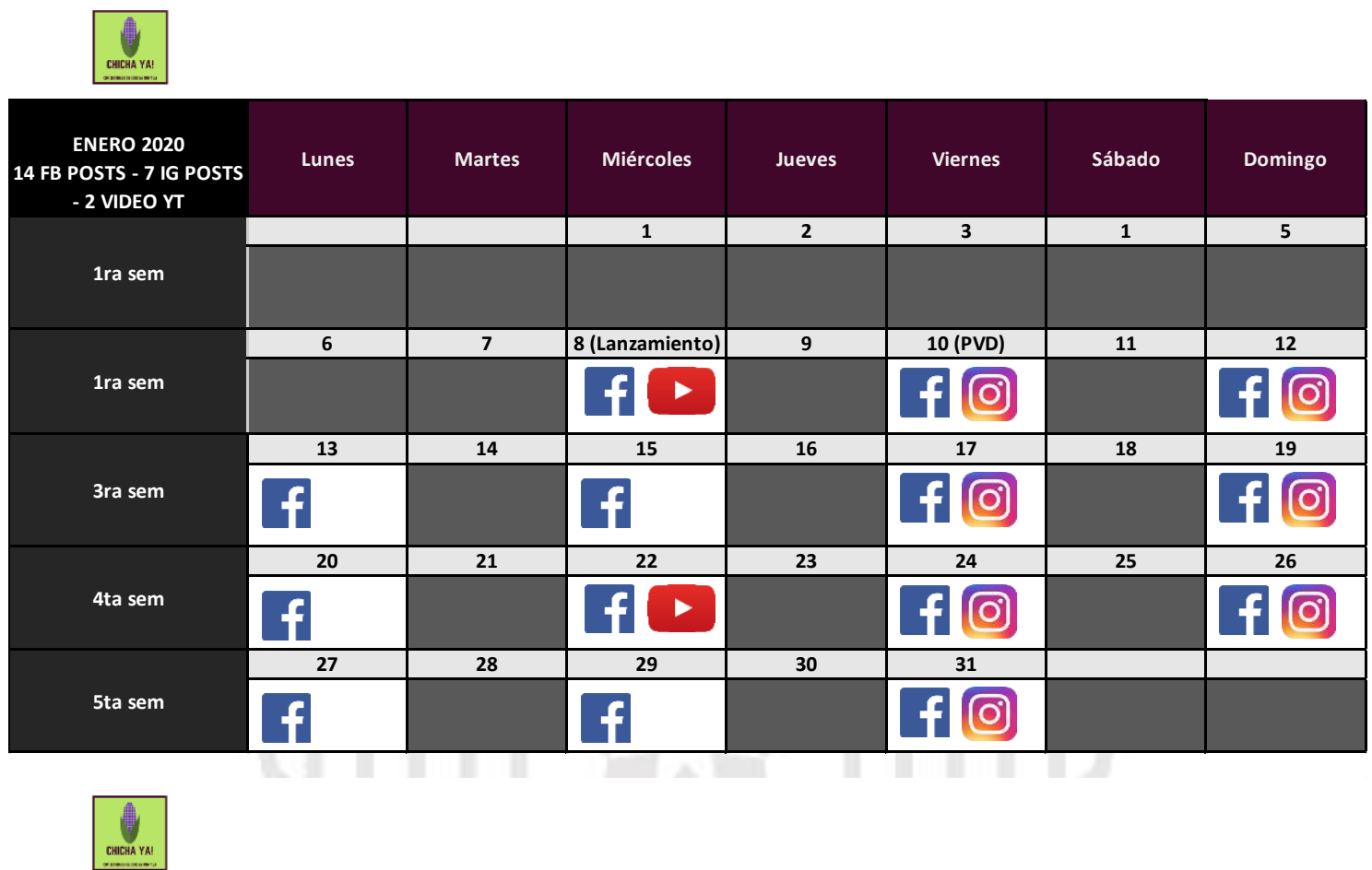

\begin{tabular}{|c|c|c|c|c|c|c|c|}
\hline $\begin{array}{c}\text { FEBRERO } 2020 \\
16 \text { FB POSTS - } 8 \text { IG } \\
\text { POSTS - } 1 \text { VIDEO YT }\end{array}$ & Lunes & Martes & Miércoles & Jueves & Viernes & Sábado & Domingo \\
\hline \multirow[b]{2}{*}{ 1ra sem } & & & & & & 1 & 2 \\
\hline & & & & & & & \\
\hline \multirow[b]{2}{*}{ 2da sem } & 3 & 4 & 5 & 6 & 7 & 8 & 9 \\
\hline & & & & & & & \\
\hline \multirow[b]{2}{*}{ 3ra sem } & 10 & 11 & 12 & 13 & 14 & 15 & 16 \\
\hline & & & & & & & \\
\hline \multirow[b]{2}{*}{ 4ta sem } & 17 & 18 & 19 & 20 & 21 & 22 & 23 \\
\hline & & & & & & & \\
\hline \multirow[b]{2}{*}{ 5ta sem } & 24 & 25 & 26 & 27 & 28 & 29 & \\
\hline & & & & & & & \\
\hline
\end{tabular}




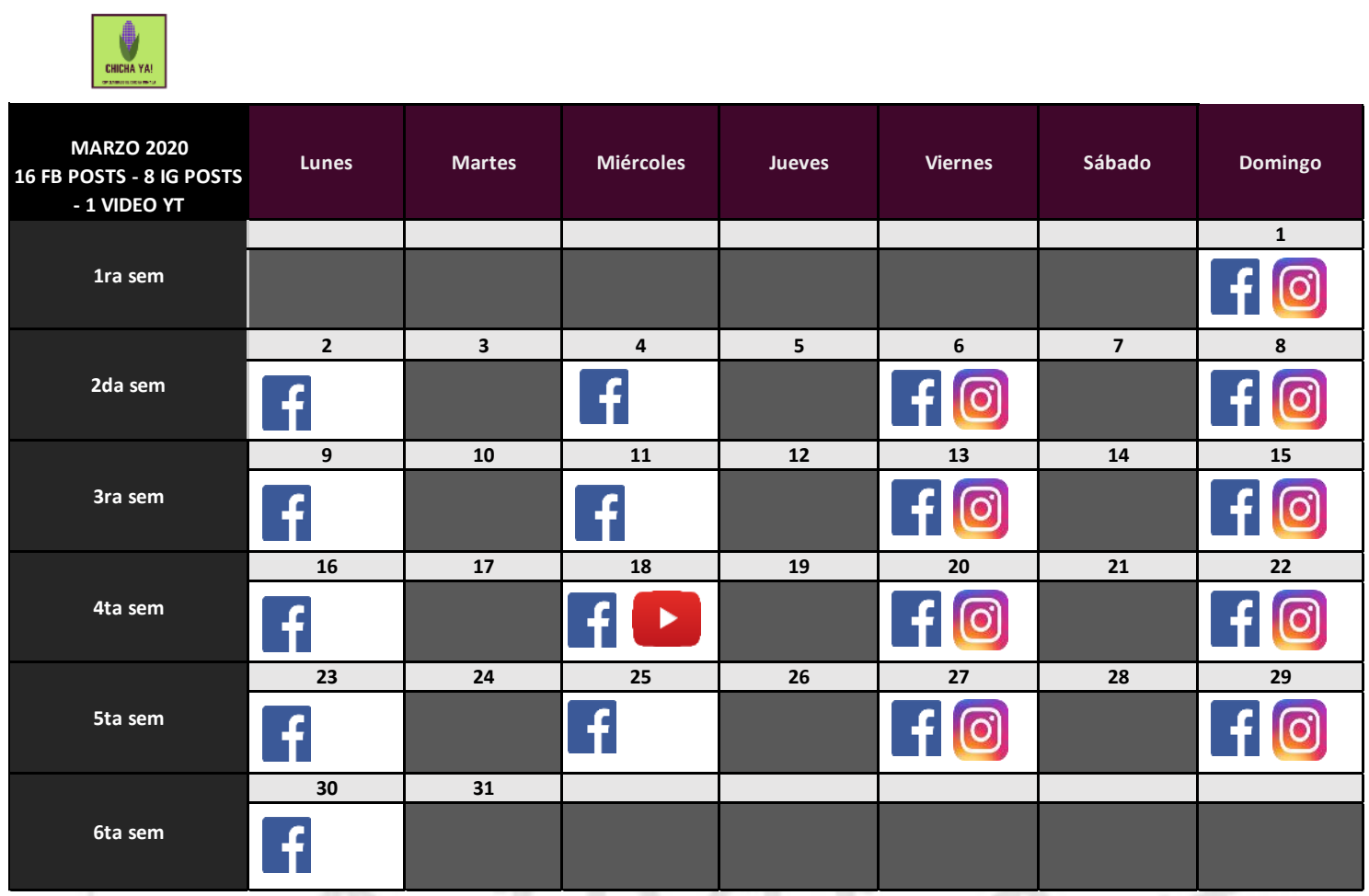

